\title{
Research Paper \\ A Study of the Relationship Between Poverty and Social Capital: A Case Study From Sistan and Baluchestan Border Settlements
}

\author{
*Faramarz Barimani ${ }^{1}$, Hadi Rasti ${ }^{2}$, Meisam Dahani ${ }^{3}$, Raziyeh Jahantigh ${ }^{4}$
}

1. Associate Professor, Department of Geography, Faculty of Humanity \& Social Sciences, University of Mazandaran, Babolsar, Iran.

2. PhD Candidate, Department of Geography and Rural Planning, Faculty of Geographical Sciences and Planning, University of Isfahan, Isfahan, Iran

3. MA, Department of Geography and Rural Planning, Faculty of Geographical Sciences and Planning, University of Isfahan, Isfahan, Iran.

4. MA, Department of Geography and Rural Planning, Faculty of Geography and Environmental Planning, University of Sistan and Baluchestan, Zahedan, Iran.

Cftation: Barimani, F., Rasti, H., Dahani, M., \& Jahantigh, R. (2016). A Study of the Relationship Between Poverty and Social Capital: A Case Study From Sistan and Baluchestan Border Settlements. Journal of Rural Research. 7(3), 438-453. http://dx.doi.org/10.21859/jjr-07032

dol: $:$ http://dx.doi.org/10.21859/jjr-07032

Received: 27 May. 2016 Accepted: 5 Aug. 2016

Key words: Poverty, Social capital, Settlements of borders, Sistan and Baluchestan, Iran

\begin{abstract}
A B STRACT
Settlements located in border areas, especially rural areas, are in lower level of social capital. Poverty is one of the key contributing factors for this. The aim of this research was to explore the relationship between poverty and social capital in the theoretical framework of social depilation. The type of research is descriptive-analytic and correlation. Due to widespread population, 382 households and 136 people of local manager among the three township (Mirjaveh, Saravan and Zahak) were sampled by cochran. The data were collected using a questionnaire and analyzed by fuzzy logic (MATLAB software) and SPSS (Statistical package for social sciences). The findings indicate a relatively high degree of correlation between social capital and poverty with a degree $(0.628)$ and $(0.602)$ and a negative impact of poverty on social capital. So that poverty explains 79.2 percent of the social capital, and edit as per unit change in the poverty rate $(-0.890)$ Change will be created in the social capital. Among the indicators of poverty, "culture of poverty" and then "social rejection" have the most influence on social capital. The results indicate that the level social capital in this kind of settlements, strongly is under the influence of poverty. So if perpetuation of poverty, accompanied with the trend of gradual reduction of social capital (trust, participation and social solidarity) continue, it is possible the region in the future faced, the unstable upper, which in that case, control it will be difficult.
\end{abstract}

\section{Extended Abstract}

\section{Introduction}

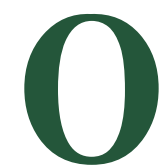

ne of the most important effects and consequences that poverty can cause in human society is to undermine the social capital or at least prevent its growth. In this regard, collier has stated that poverty impacts more on social capital than social capital affects on poverty. This phenomenon is reflected more in underdeveloped border areas than other areas. Border areas in Iran are sensitive and strategic areas. Nature of isolated in border areas, especially in mountainous and desert areas, steadily because of a lack of welfare and lack of motivation for the life of the was underlying political, economic and security problems for governments. In this regard, environmental injustice, and unbalanced development in geographical areas of the country, especially in border areas of southern east the country caused a split 
in national unity and lead to divergent provocations response, and despite efforts that after the islamic revolution has been done in order to overcome deprivation the less developed areas of border the south east areas, again because such as geographical isolation, increase of feelings of discrimination and class, crisis of unemployment, drug trafficking and commodities, immigration and the factors limiting of investment security, caused the remaining areas of the development cycle, and development indicators they are not at a desirable level. Hence, the present study scrutinized relationship between poverty and social capital in the theoretical framework of social ostracism, in the border areas of Sistan and Baluchestan (Mirjaveh, Saravan and Zahak Township).

\section{Methodology}

Method research in his study is analytic-descriptive and correlation. Among the study population, 518 cases from residents of border areas of east of Iran located in Sistan and Baluchestan (Mirjaveh, Saravan and Zahak Township), 24 rural settlements and 4 urban settlements (rural-urban) have been selected and sampled by cochran. With the extraction, factors and variables, literature, questionnaires were prepared. Validity and reliability of the instrument was done by experts and judged by cronbach's alpha (0.796 to 0.901$)$ respectively. After collecting research data, analysis was done using fuzzy logic in the toolbox in Matlab, and using statistical software, SPSS.

\section{Results}

The findings show that the poverty and the social capital are respectively with the rank of 0.602 and 0.628 . Among the indicators of poverty, "position of poverty" with the grade 0.686 and among the indicators of social capital, "social participation" with the grade 0.667 were assigned the highest rank. Findings also indicate a negative impact of poverty on social capital, so that $79.2 \%$ of social capital in the study area is related to changes in poverty rates and per unit change in the level of poverty happens in the area, -0.890 changes in social capital. In the meantime, indicator "culture of poverty", in explanation of social capital (social trust, participation and cohesion) from other poverty indicators has role and impact more prominent. Position of poverty, with less impact only shares somewhat in explaining changes in social trust and participation. According to the findings poverty has high impact in reducing the ablation of social capital, in this border region.

\section{Discussion}

In the study area, the problem of social capital reduction, due to poverty, can be related to unequal power relations and therefore unbalanced distribution of resources, social and economic services, and opportunities, especially employment and income opportunities as well as inequality in access to financial and social services. Since the study area is geographically isolated and its inhabitants usually do not share in national and regional programs, their access to economic opportunities and production infrastructures is minimal, naturally poverty finds a favorable footing in these areas. The root of the problem must be sought in the inefficiency of border management and unequal regional and local development. Having security view toward the border and lack of opportunity-based approach to border areas on the one hand, and unequal distribution of assets, facilities, services, opportunities and socioeconomic facilities, in regional and local level, lack of attention to the role of people in border management and most importantly the fundamental weakness of the local economic infrastructure on the other hand, are considered prominent manifestations of this ineffectiveness. Hence it seems that "position of poverty" in the region is the main factor of the decline of social capital. Because the culture of poverty and social exclusion according to Alkak, Marx, Andrew and De Haan views are rooted in position of poverty, which is derived from social construction and unequal distribution of power.

\section{Conclusion}

The results indicate strong influence of social capital caused by poverty in the border region under study. The prominent status of poverty is related to the shortcomings of the local economy that is the most important cause of poverty in the study area. So if poverty continues with gradual decline in social capital (social trust, participation and cohesion), it is likely that in the future the region becomes unstable and its control will become difficult. 


\title{
تحليل رابطه فقروسرمايه/جتماعى؛مطالعهموردى:سكونتكاههاى مرزى استان سيستانوبلوجستان
}

\author{
"فرامرز بريمانى '، هادى راستى ‘ ميثم دهانى"، راضيه جهانتيغ" \\ ا 1- دانشيار، كروه جغرافيا، دانشكده علوم انسانى و اجتماعى، دانشكاه مازندران، بابلسر، ايران.

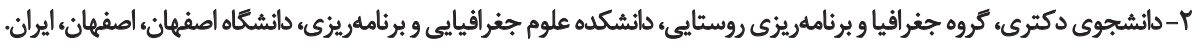

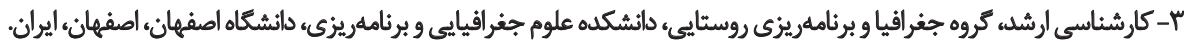

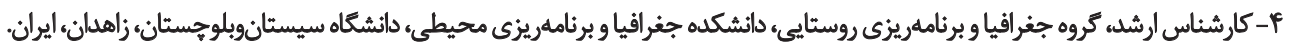

\begin{abstract}
حكبن

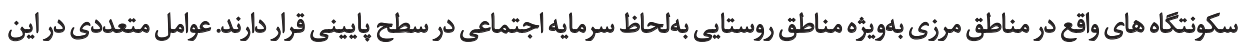

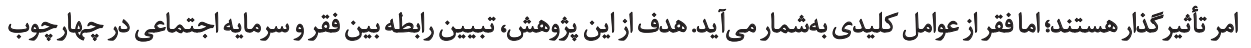

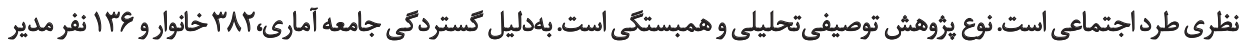

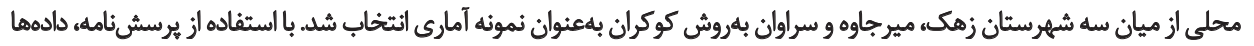

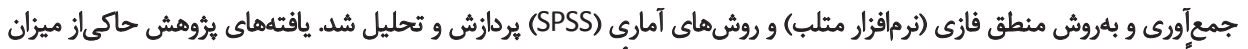

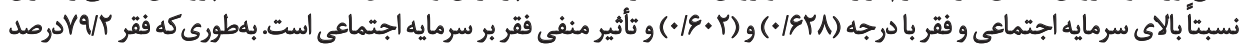

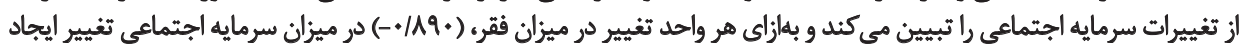

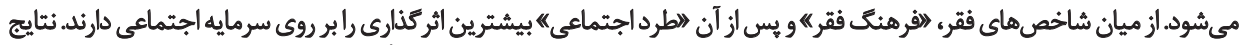

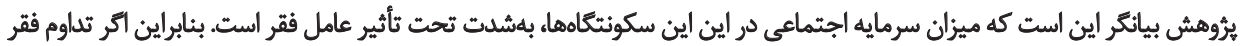

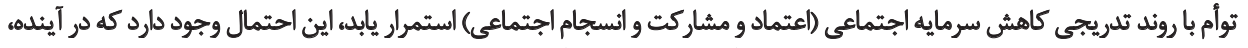

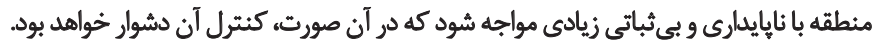

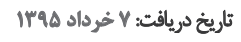

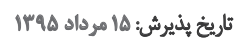

كليدوازوها:

فقر، سرمايه اجتماعى،

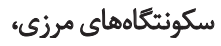

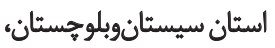
ايران

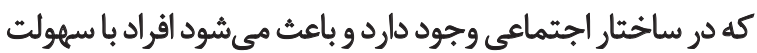

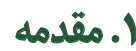

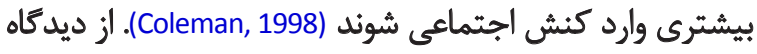

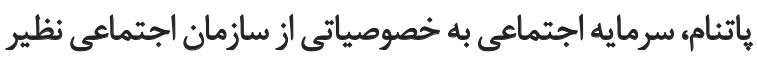

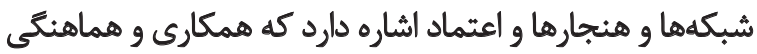

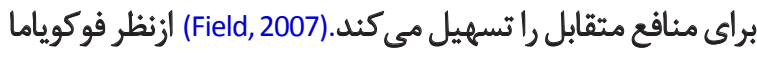

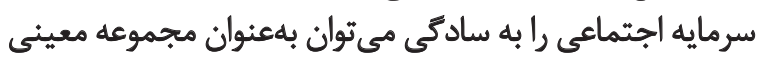

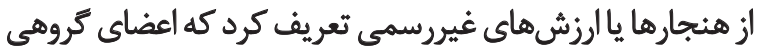

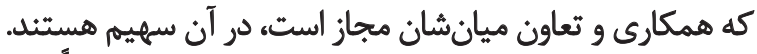

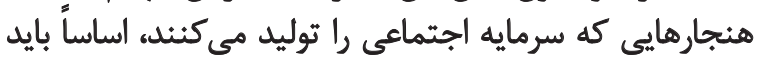

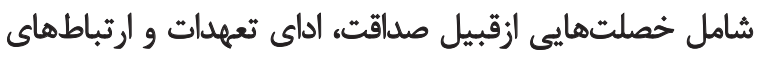

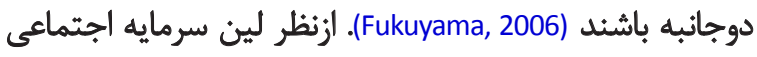

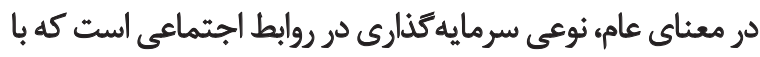

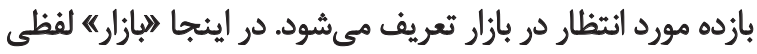

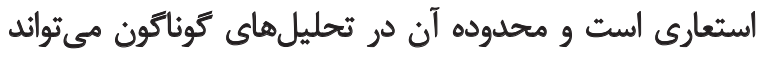

فقر ضمن نارسايىهاى شغلى و مالى، شرايطى را دربرمى كيرد

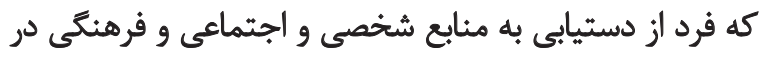

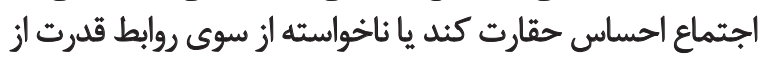

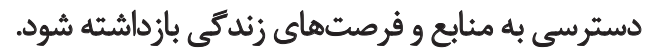

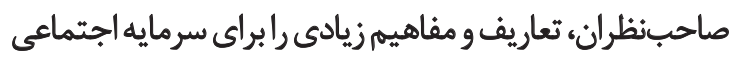

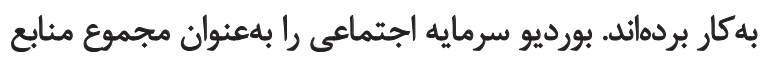

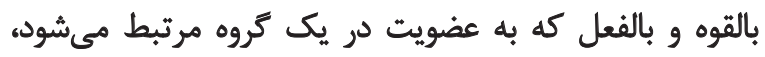

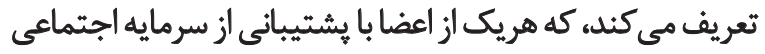

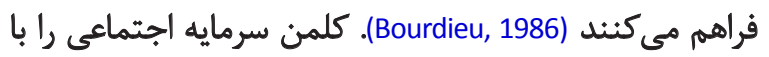

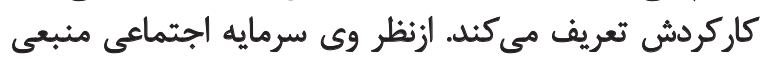

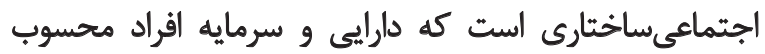

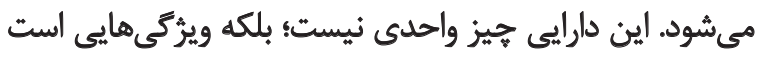


مهاجرت و عوامل محدود كنينده امنيت سرمايه كَّارى، باعث شده

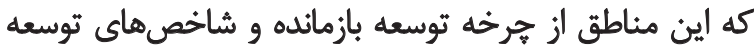

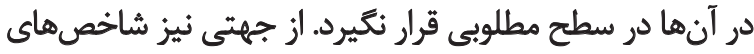

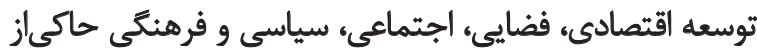

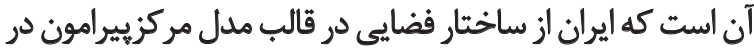

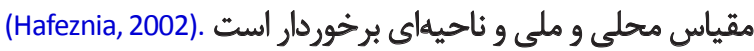

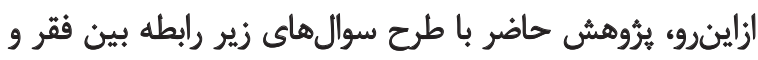

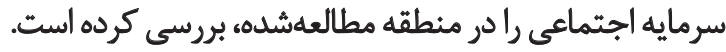
ميزان فقر و سرمايه اجتماعى در محدوده مرزى مطالعهشده

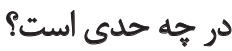
آيا بين فقر و سرمايه اجتماعى در محدوده مطالعهشده رابطه

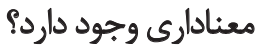

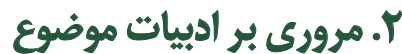

در ارتباط با فقر و سرمايه اجتماعى در جهان و ايران مطالعاتى بهان

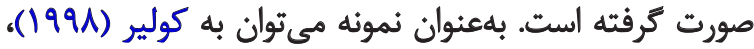

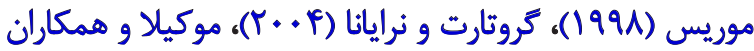

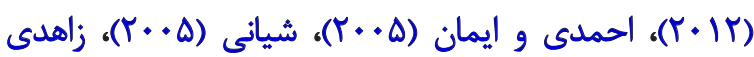

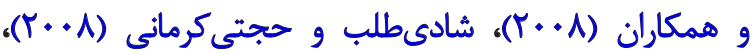

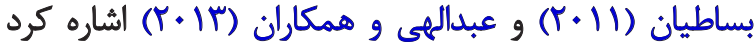

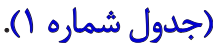

" ب. روش شناسى تحقيق

نظر يه فر هئَى فقر

اين نظريه را اسكار لوئيس مطرح كرد. ازنظر لوئيس، فقر

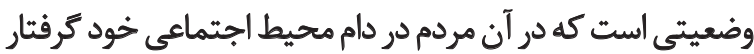

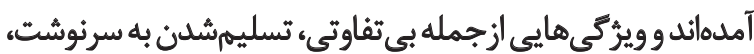

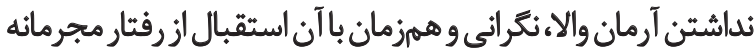

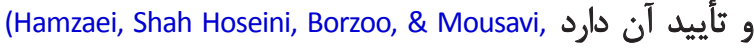

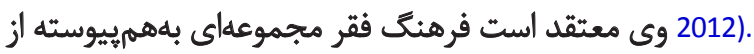

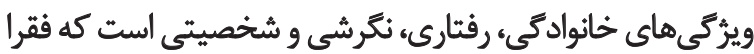

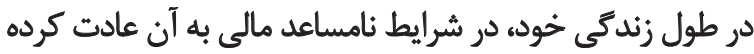

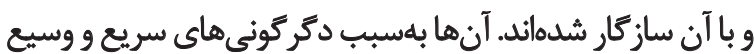

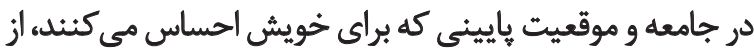

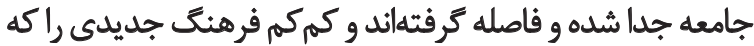
با فرهنغَ عموم جامعه متفاوت است، ايجاد مي كنيند.

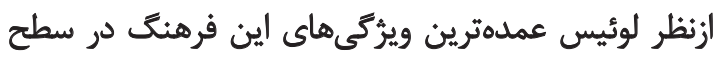

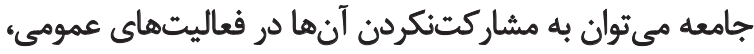

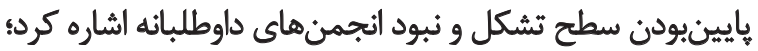

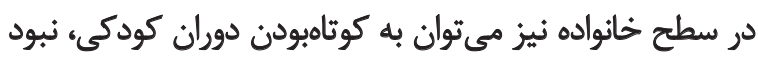

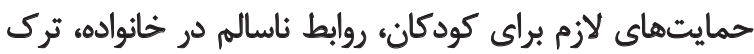

اقتصادى، سياسى، اجتماعى يا بازاركار باشد كه در آن، افراد با

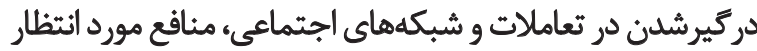

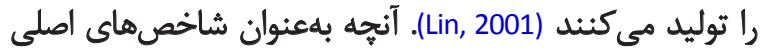

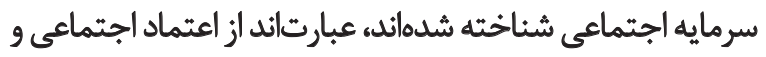

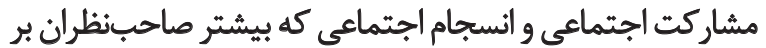

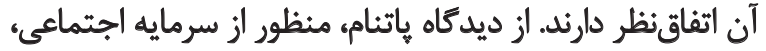

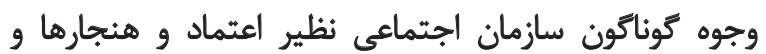

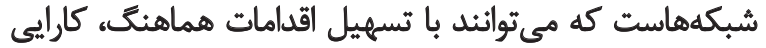
جامعل وا بهبود بخشيند (Putnam, 1995).

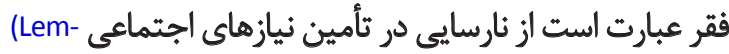

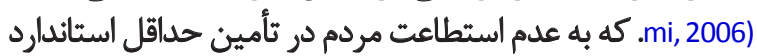
زندگى اشاره دارد (Moore, 2000; Alexiedou, 2005)، و بيانكتر

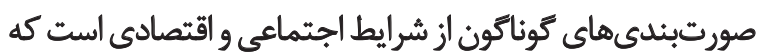

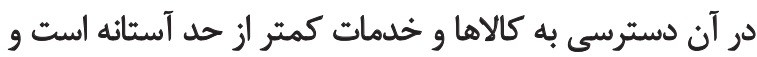

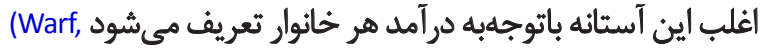
أنما

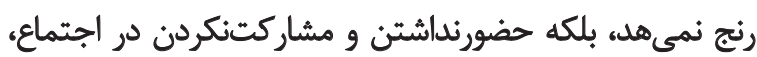

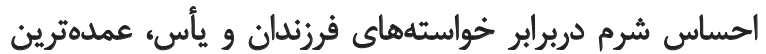

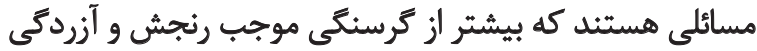

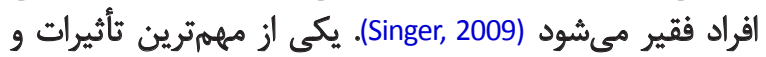

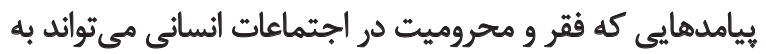

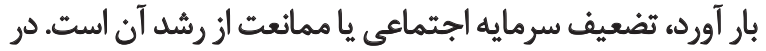

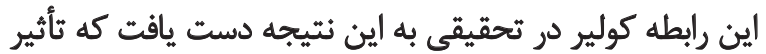

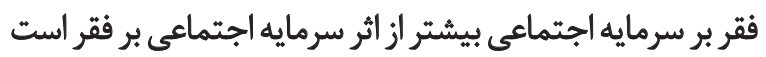
.(Collier, 1998)

زاهدى و همكاران طى يثروهشى به اين نتيجه رسيدند كه

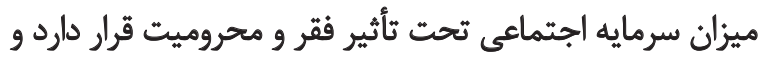

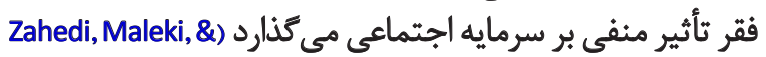
Heydari

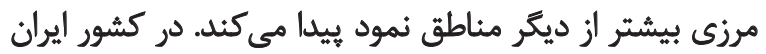

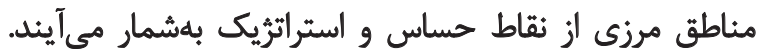

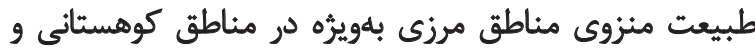

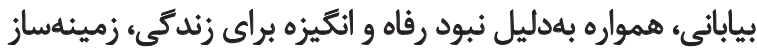

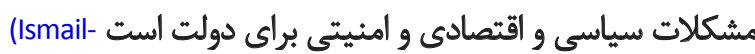

Zadeh, 2008

در همين راستا بيعدالتىهاي محيطى و توسعه نامتوازن

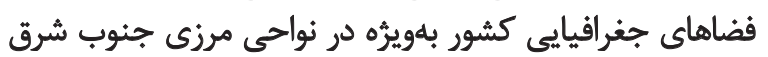

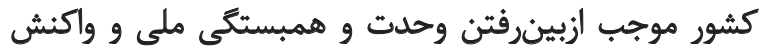

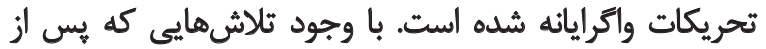

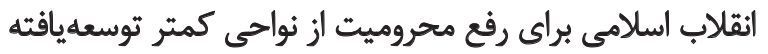

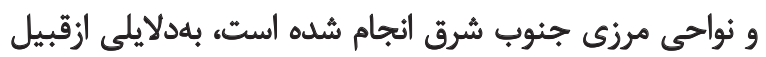

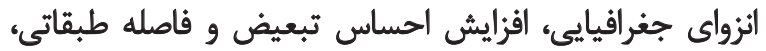

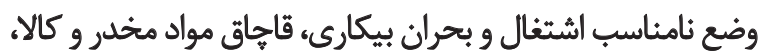


جدول ا. برخى مطالعات خارجى و داخلى انجامشده درزميئه موضوع يروهش.

\begin{tabular}{|c|c|c|c|c|}
\hline متغير هاي برورسي شيده & ابعاد و شاخحصها & 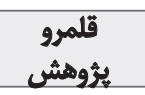 & محققان و سال & \\
\hline 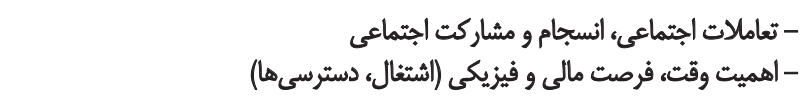 & - فسر مايه اجتمائي - فقرم & - & كولير (1941) & \\
\hline 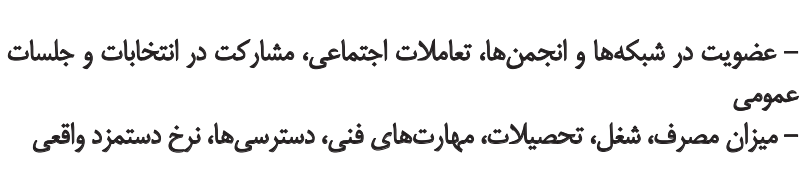 & 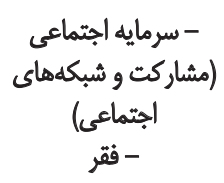 & هندوسثان & موريس (194) & \\
\hline 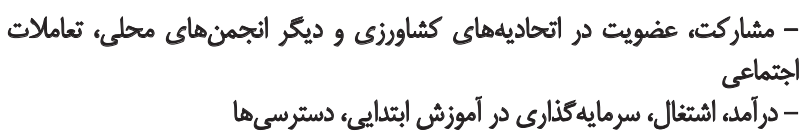 & 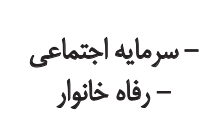 & بوليوى & 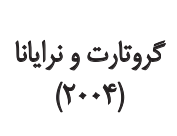 & خارجى \\
\hline 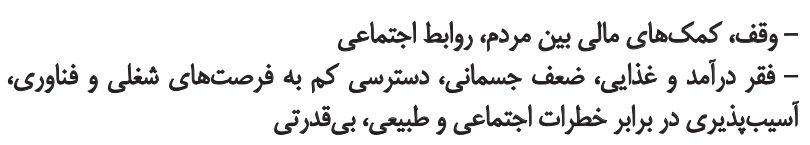 & 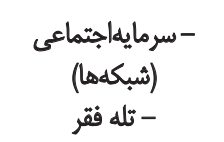 & - & 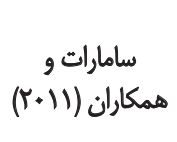 & \\
\hline 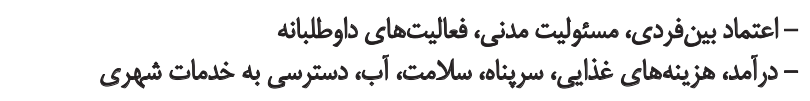 & - سرعايه اجتماعى - فقر & كينا (نيجريه) & 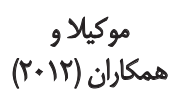 & \\
\hline 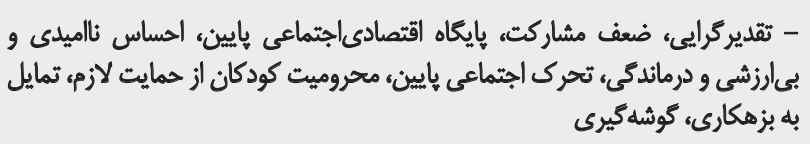 & 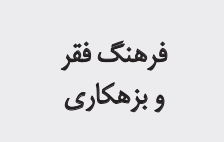 & شيراز (ايران) & $\begin{array}{c}\text { احمدى و ايمان } \\
(Y+\Delta)\end{array}$ & \\
\hline 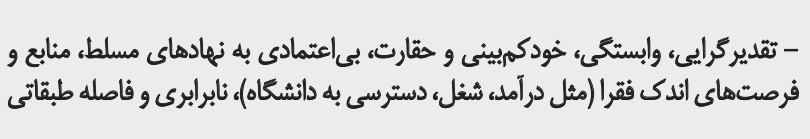 & 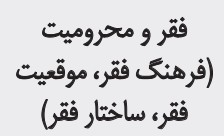 & ايران & شياني (ه.+r) & \\
\hline 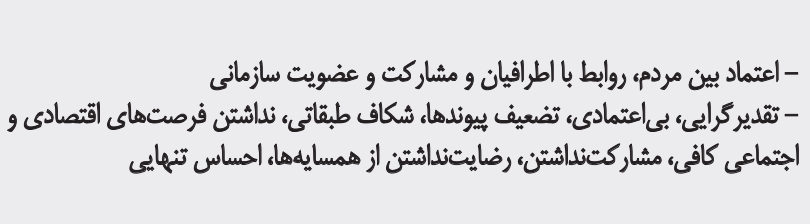 & 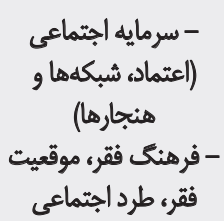 & شهرستان & همكاران (r) & \\
\hline 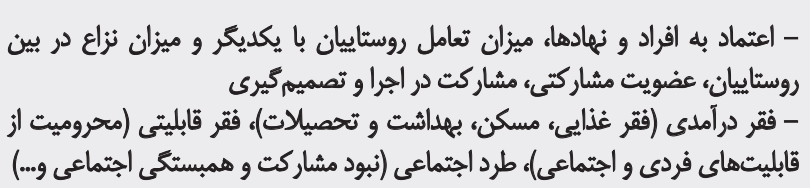 & 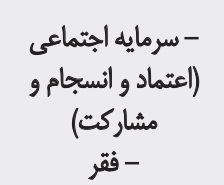 & اوبستاهاى & 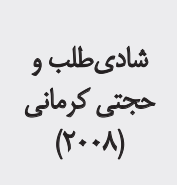 & داخلى \\
\hline - ثقديركرايي، مصرفكرايع، بيكانكي اجتماعي، نيود آيندهنكرى و ئبود سرزتش فقر & فرهنى فقر & دلفان (ايران) & بساطيان (1I. (T) & \\
\hline 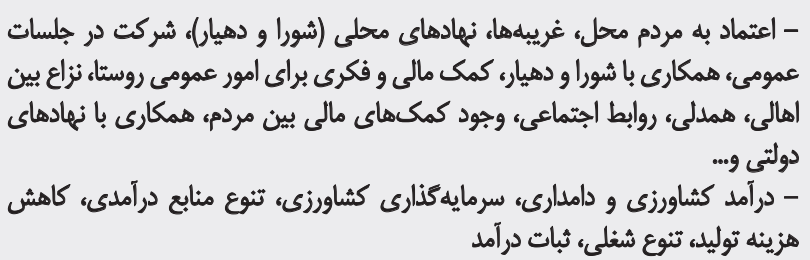 & 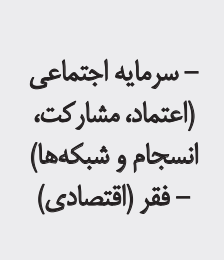 & ميائلوآب & 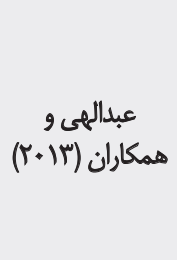 & \\
\hline
\end{tabular}




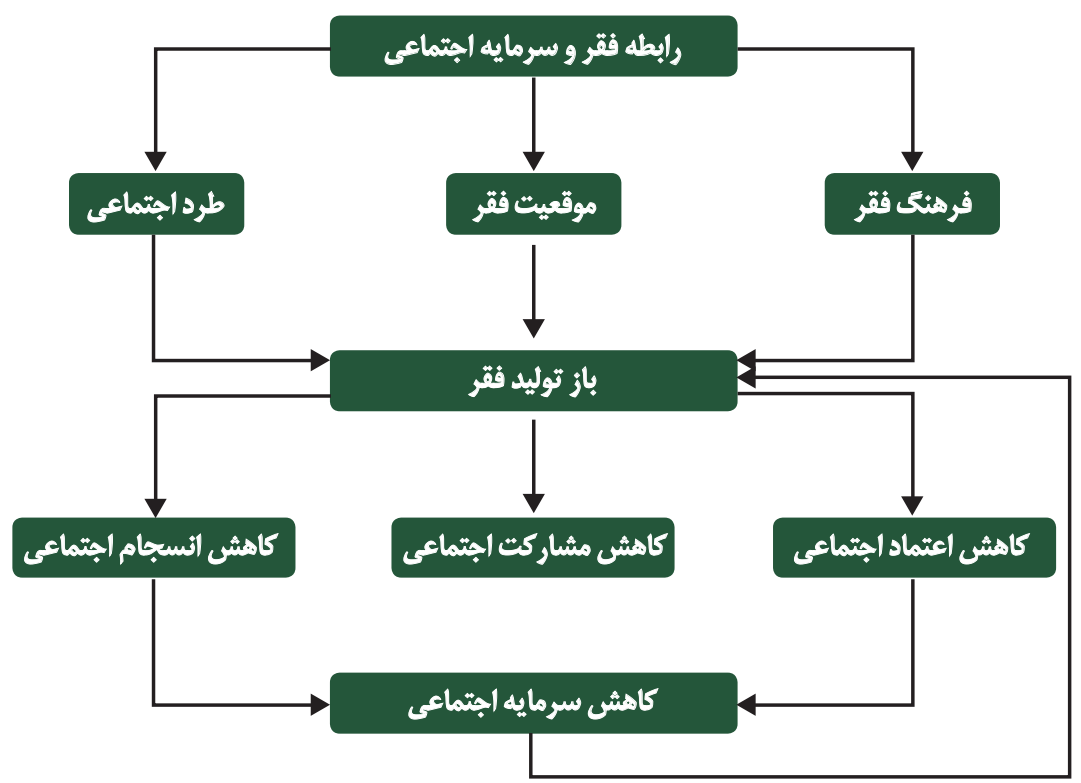

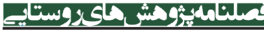

نقطه مقابل وضعيت مبتنىبر اعتماد بالا، مشاركت فعال،

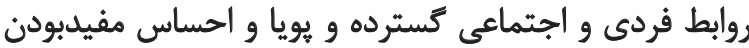

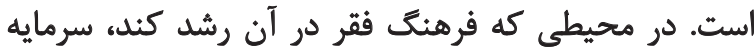

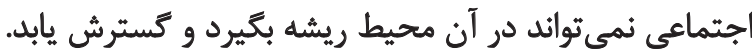

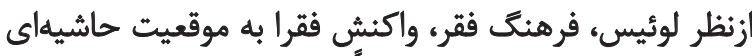

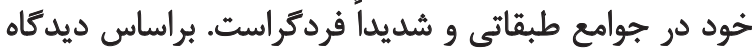

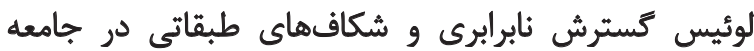

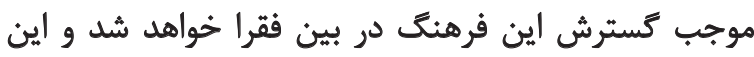

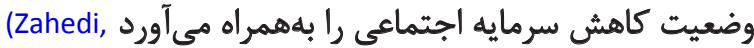
.et al., 2008)

$$
\text { تصوير ا. مل ملهومي تحقيق. }
$$

خانواده، سريرست خانوار بودن زنان، نبود حريم خصوصى و... شاره كرد (Esfandiari, 2013).

ازنظر لوئيس افرادى كه خردهفرهنگ فقر دارند در جامعه

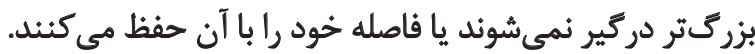

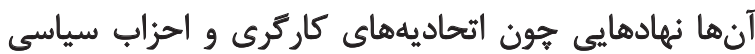

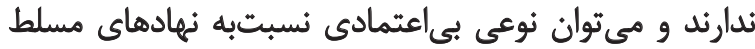

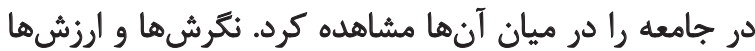

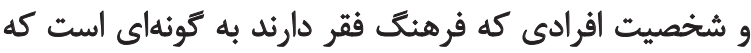

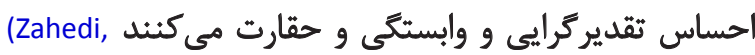

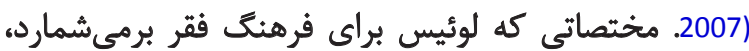

جدول †. شاخصها و متغيرهاي بررسي شده.

\section{معرفسها}

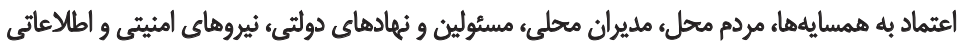
همكارى با مديران محلى، همكارى با دولث (نيروى انتظامى براى برقرارى امنيت)، شركت در أنتخابات شوراى محل، شركت در مراسم مذهبي و عمومي، تمايل به مشاركت در امور عام|المنفعه

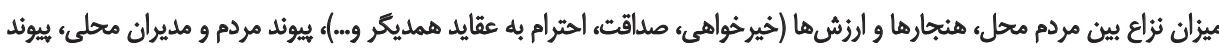

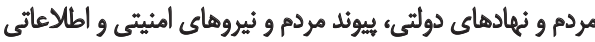

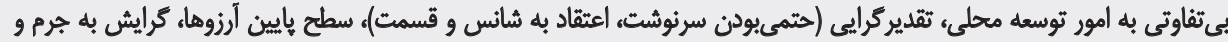

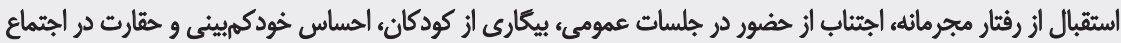

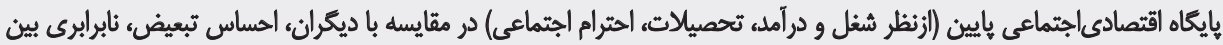

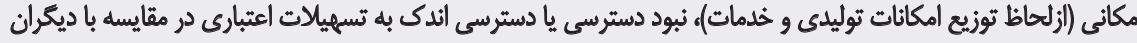

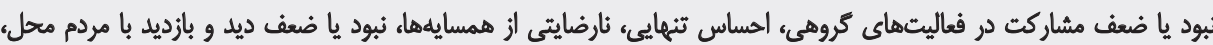

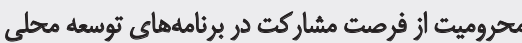

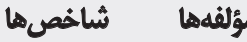

اعتماد اجتماعى

\section{سرمايه مشاركت} اجتماعى اجتماعى مثائ

انسجام اجتماعى

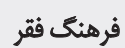

قُقتر

طرد اجتماعى

منبع: يافتههاي تحقيق، 
جدول ஈ. بروسى باياييى شاخصهاي بررسىشده.

\begin{tabular}{|c|c|c|c|}
\hline ضريب ألفا & تعداد كَويه & شاخص & مؤلفه \\
\hline . /1น & $\Delta$ & اعتماد اجتماعي & \\
\hline .19 .1 & $\Delta$ & مشاركت اجتماعيى & سرمايه اجتماعى \\
\hline$\cdot|A| F$ & 8 & انسجام اجتماعي & \\
\hline . MAY & 8 & فرهنى ققر & \\
\hline . Iva & $\Delta$ & موقعيت فَقر & فقر \\
\hline ./A9F & $\Lambda$ & طرد اجتماعي & \\
\hline
\end{tabular}

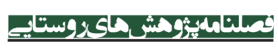

$$
\text { نظريه طرد اجثماعى }
$$

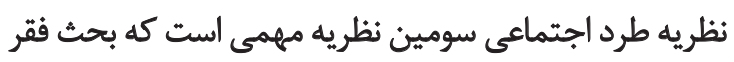

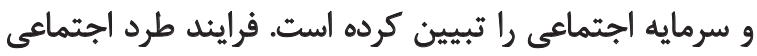

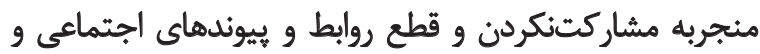

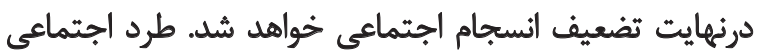

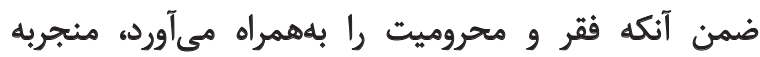

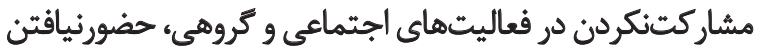

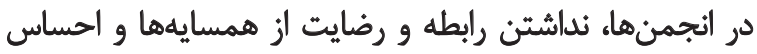

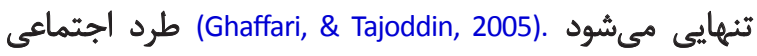

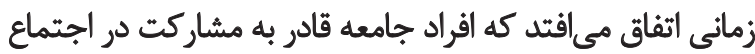

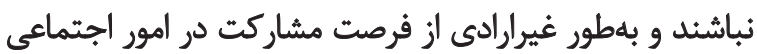

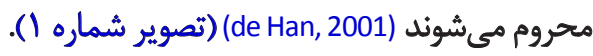

روش ششناسى

اين يُروهش از نوع توصيفىتحليلى و همبستكى است. جامعه

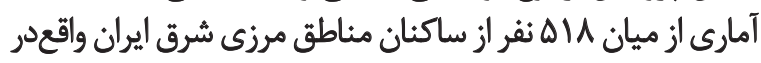

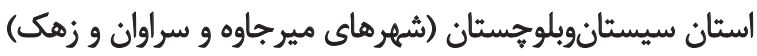

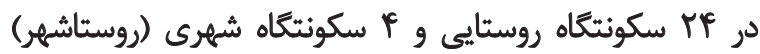
ازطريق فرمول كوكران بهاعنوان نمونه انتخاب شدنداند. با استخراج

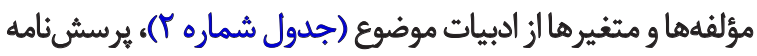

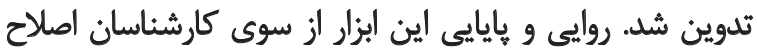

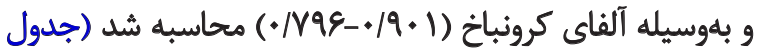

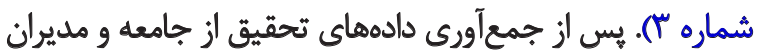

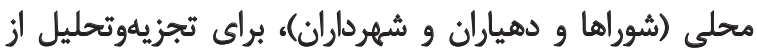

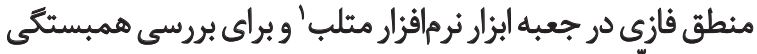

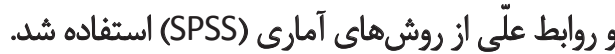

در اين يثوهش، منطق فازى در سه مرحله بلهورث زير اجرا شد: - مان

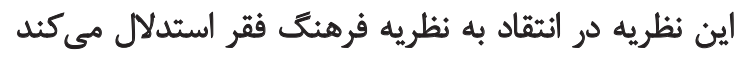

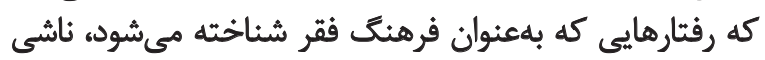

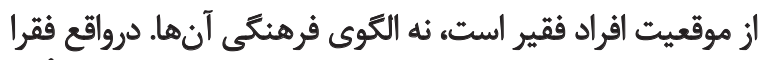

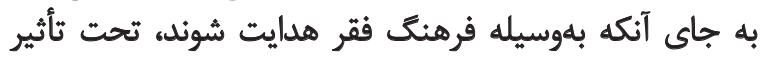

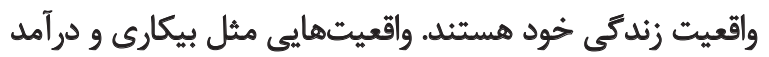

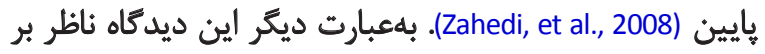

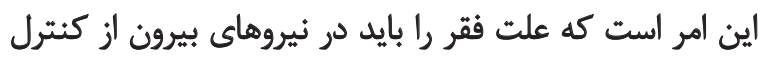

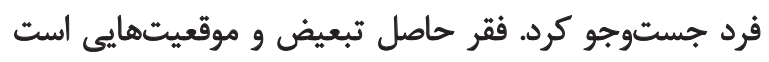
كه ساختار جامعه بر افراد تحميل كرده استر است (Esfandiari, 2013).

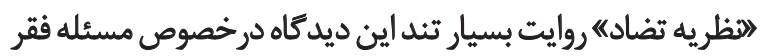

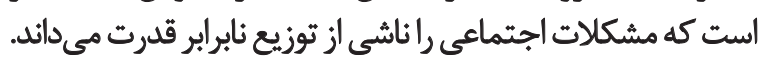

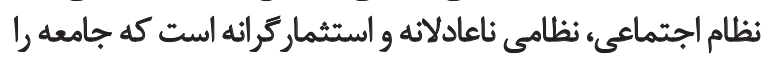

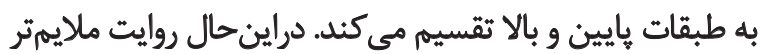

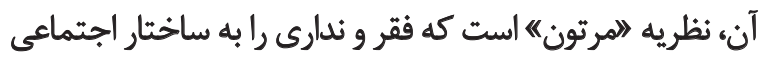
كه فرصثها را محدود مي كند، نسبث ميثر دهند

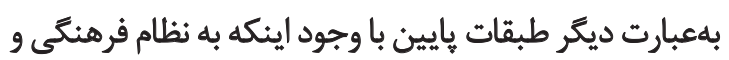

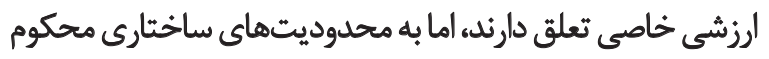

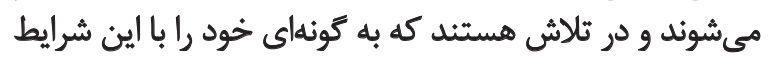

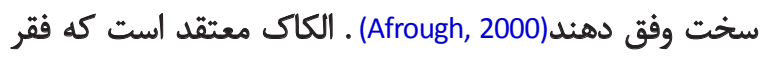

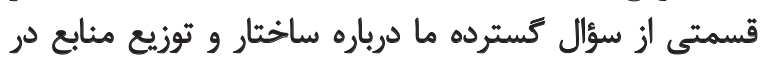

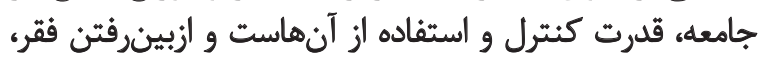

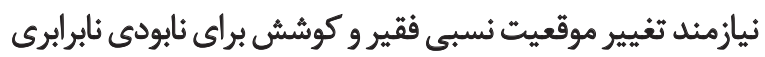

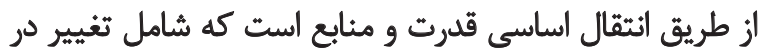

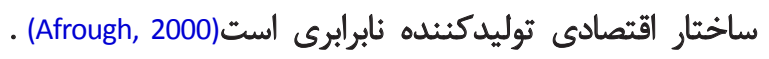

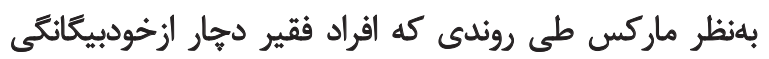

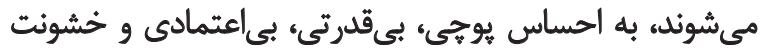

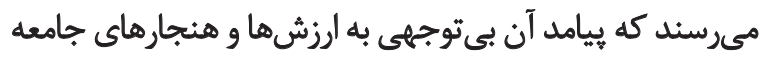

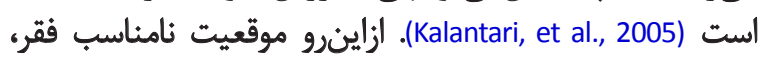
ضعف سرمايه اجتماعى را بهدنبال دارد. 


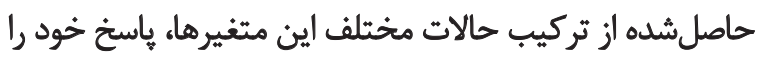

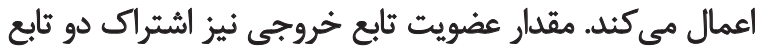

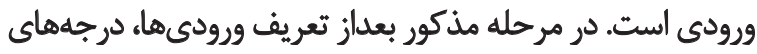

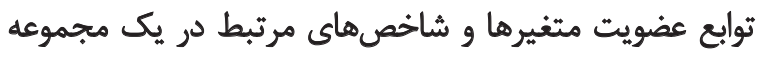

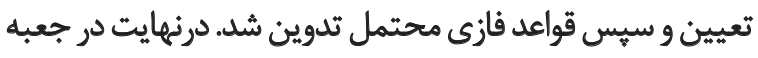
ابزار فازى در نرمافزار متلب ارزيابى و تحليل شدي شدئ دازئ

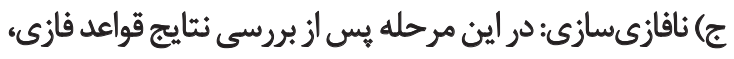

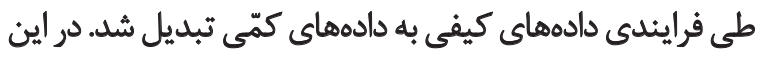

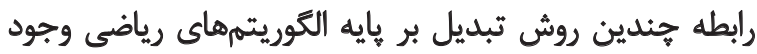

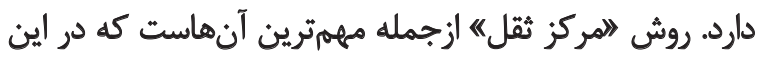
يُوهش از آن استفاده شده است (Al-jarrah \& Abu- qdais,2006).

\section{مجدووه مطالدهاشده}

محدوده مطالعهشده در اين يثروهش شامل سه شهرستان

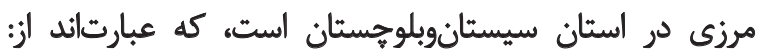

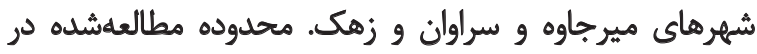

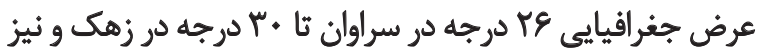

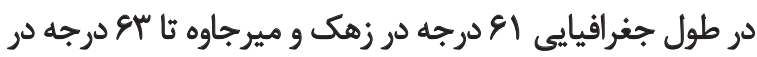

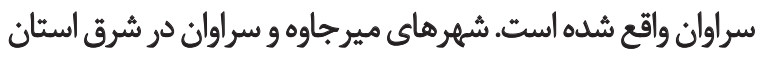

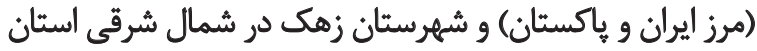

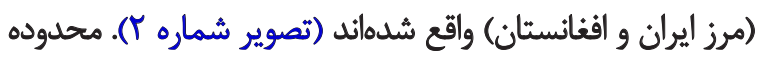

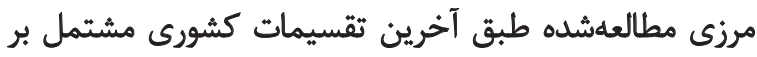

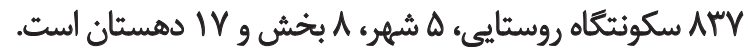

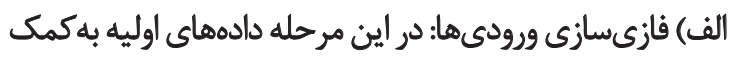

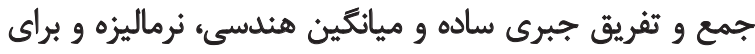

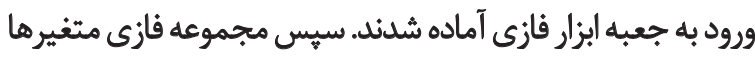

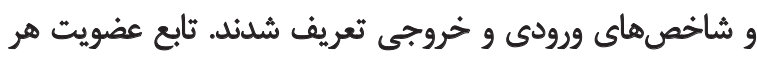

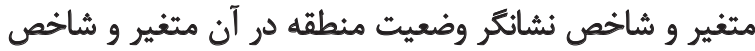

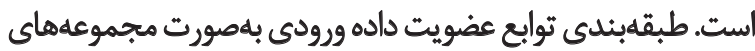

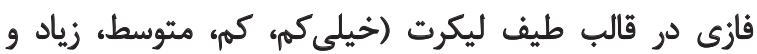

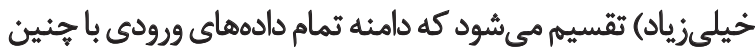

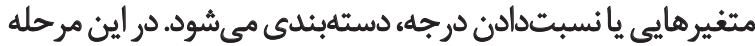

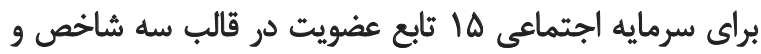

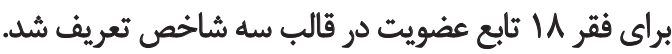

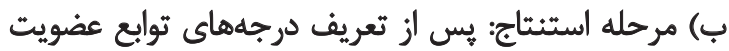

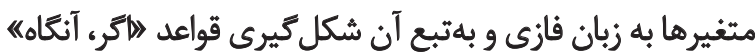

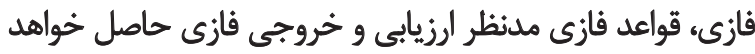

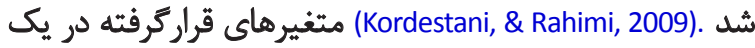

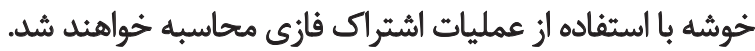

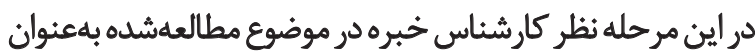

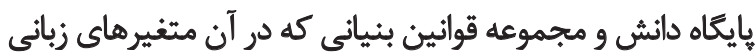

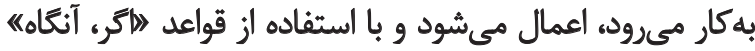

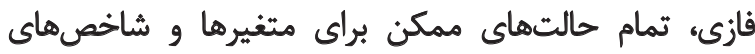

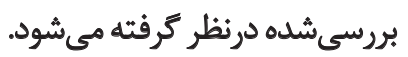
درواقع فرد خبره با استفاده ازنظر علمى و تجربه بهاي خويش،

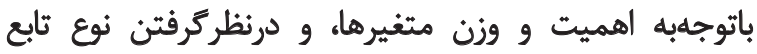

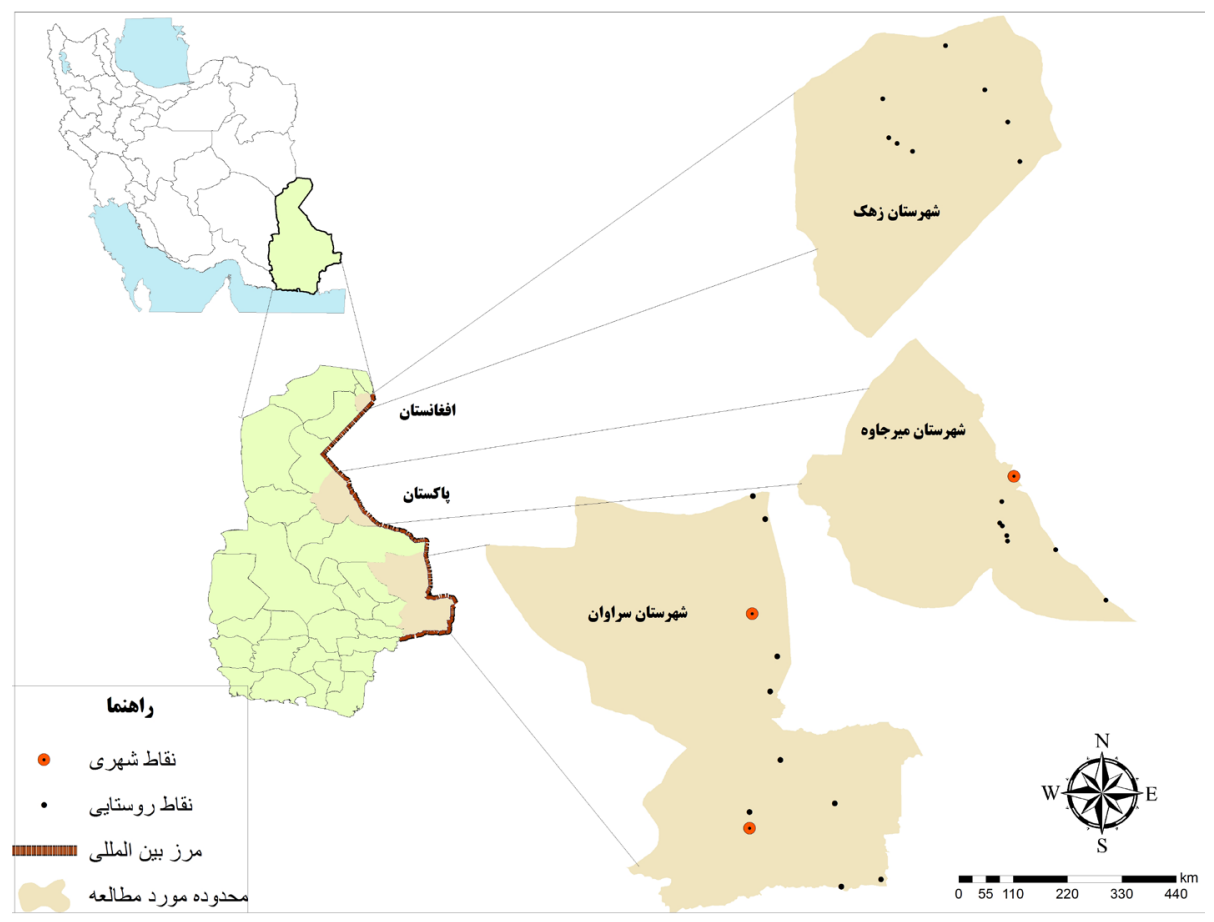




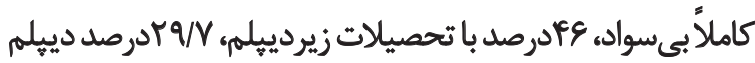

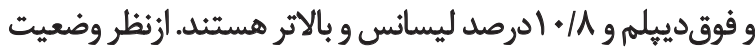

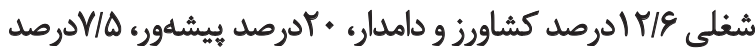

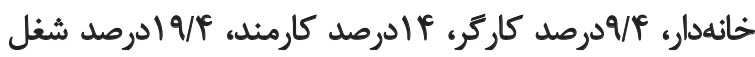

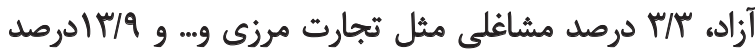

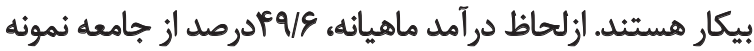

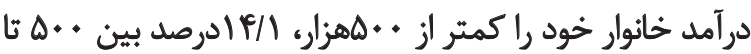

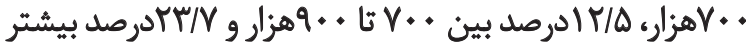

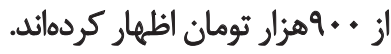

براى بررسى و سنجش ميزان فقر و سرمايه اجتماعى درمنطقه

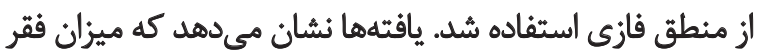

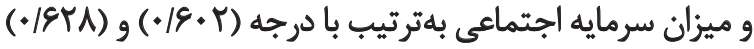

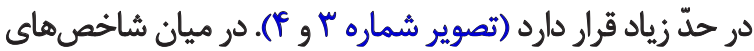

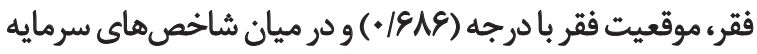

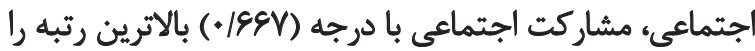

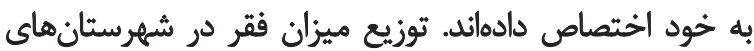

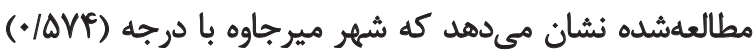

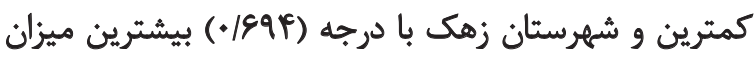
فقر در منطقه را دارند. توزيع ميزان سرمايه اجتماعى در منطقة دئه
اين محدوده طبق بهينابندى اقليمى دراستان سيستانوبلوجستان،

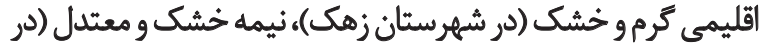
شهر ميرجاوه) و خشك و خيلى

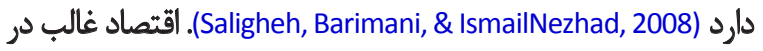

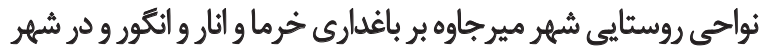

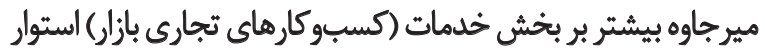

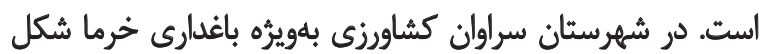

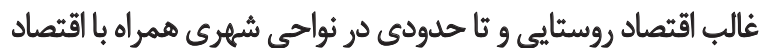

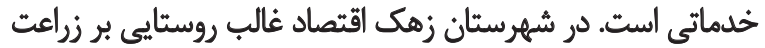

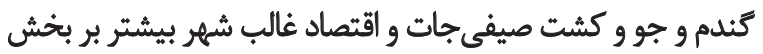

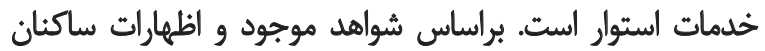

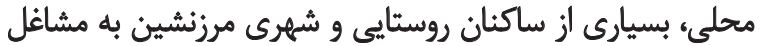

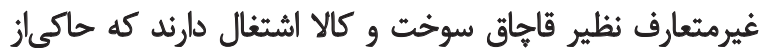

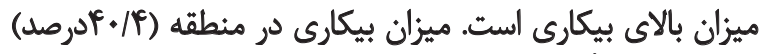
اين مسئله را تأييد مي كئد (Statistical Center of Iran, 2011).

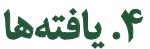

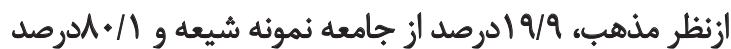

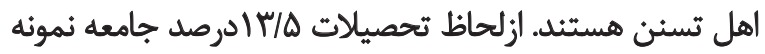

جدول F. ميزان سرمايه اجتماعى و امئيت در سكوئتكاهماي مرزى مطالعهشيده.

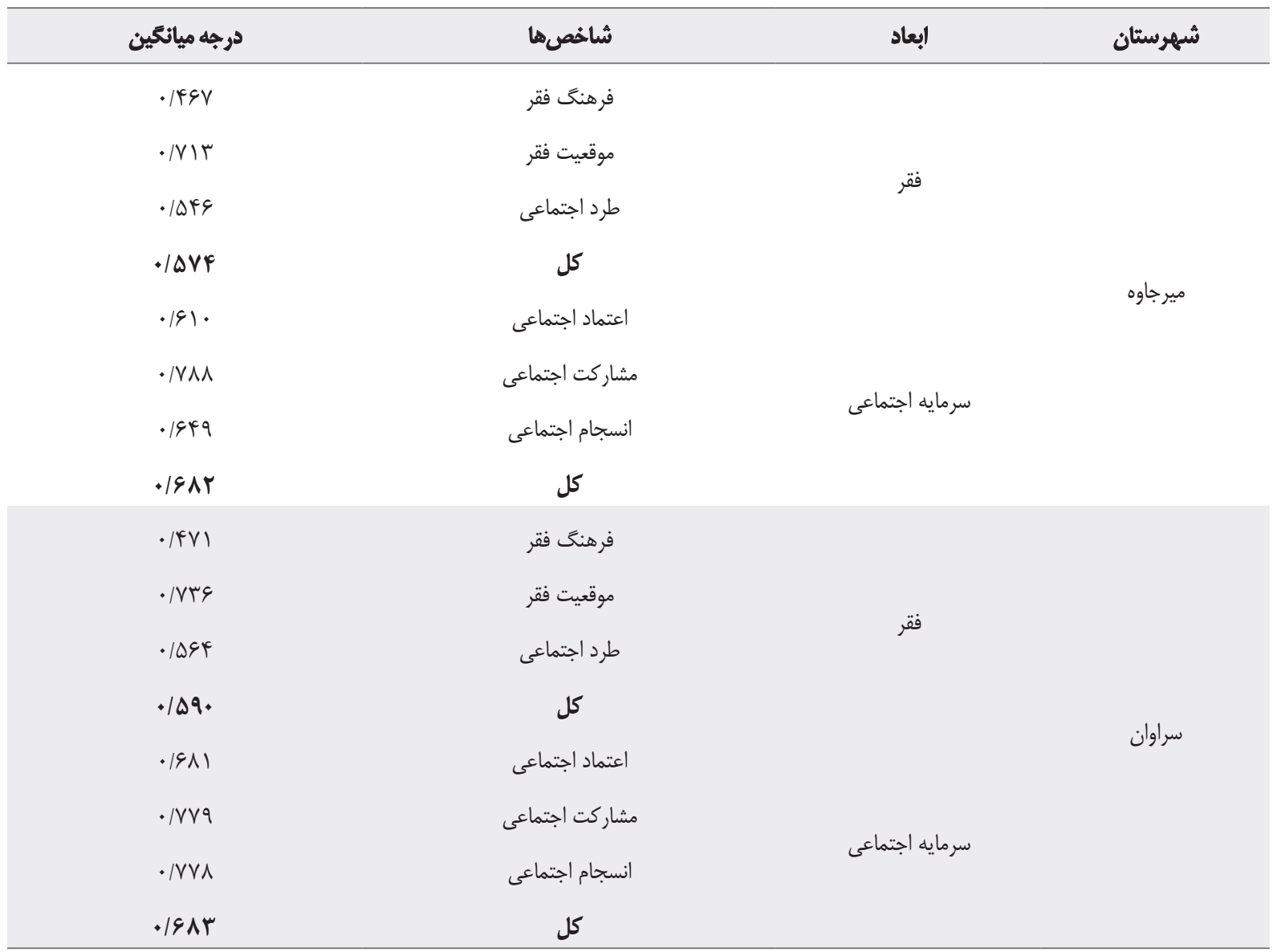




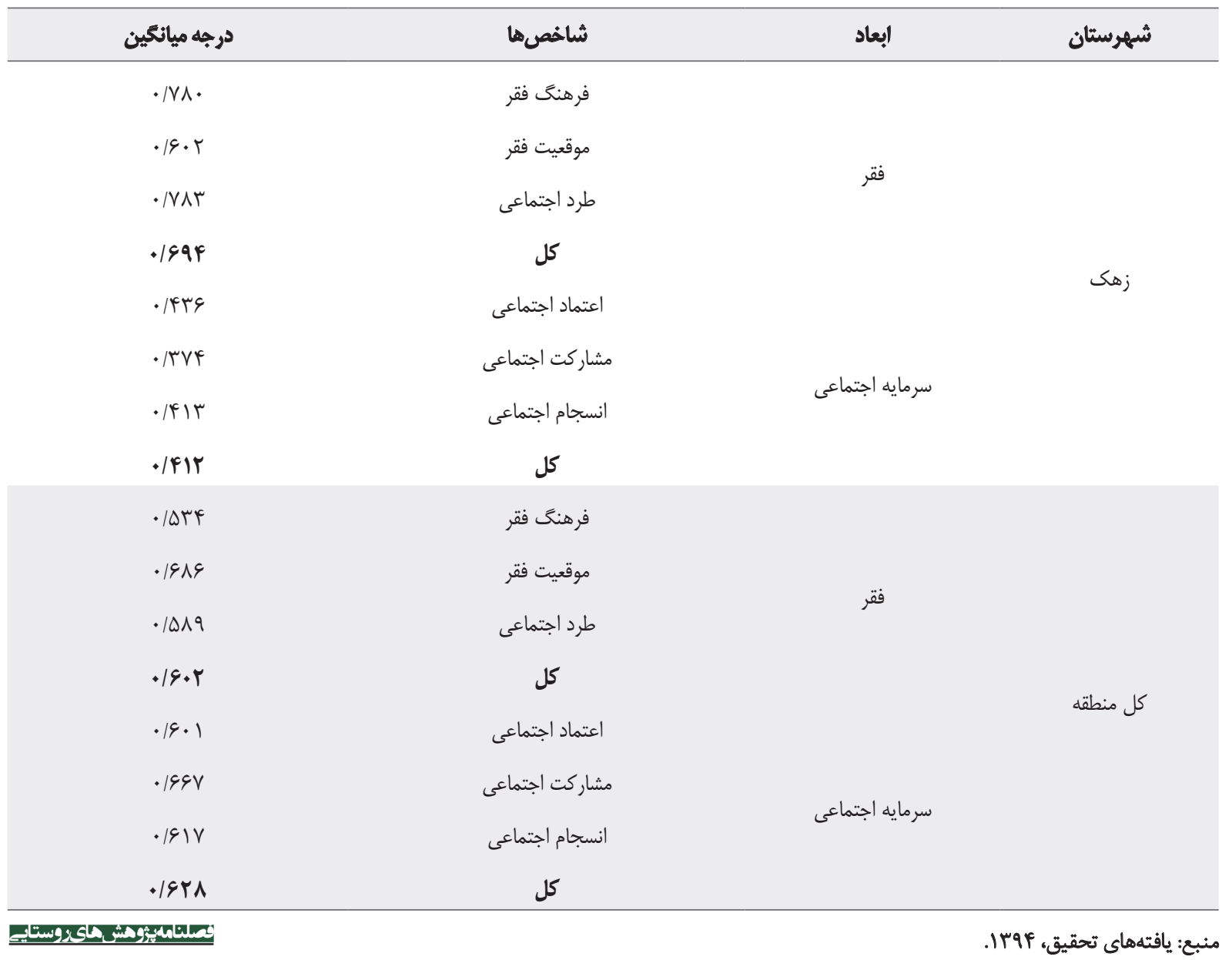

استقلال خطاها بذيرفته مىشود. مقدار ويثه، شاخص وضعيت متفيرهاي

$$
\text { متغيرهاى مستقل را تأييد مي كنيد (جدول شول شماره ه). }
$$

يافتههاى حاصل از ركرسيون ضمن اينكه كفايت خطى بونيون

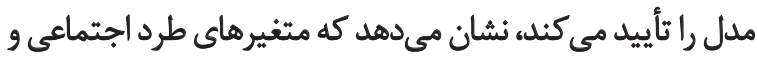

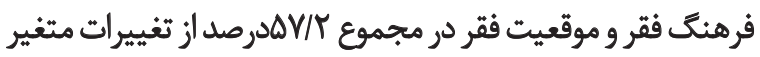

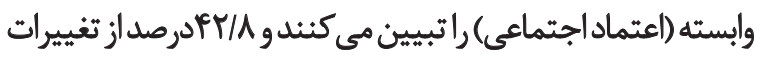

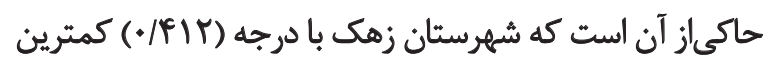

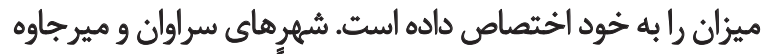

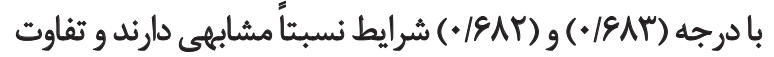

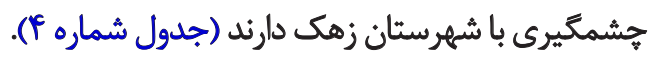
بهمنظور تبيين ثأثير فقر بر سرمايه اجتماعى از تحليل

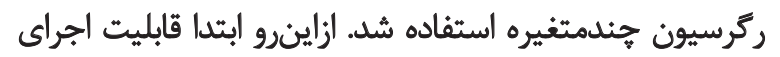
ركرسيون بررسى شد. براساس آمار آزمون دوربين واتسون إنينا قابليت فرض

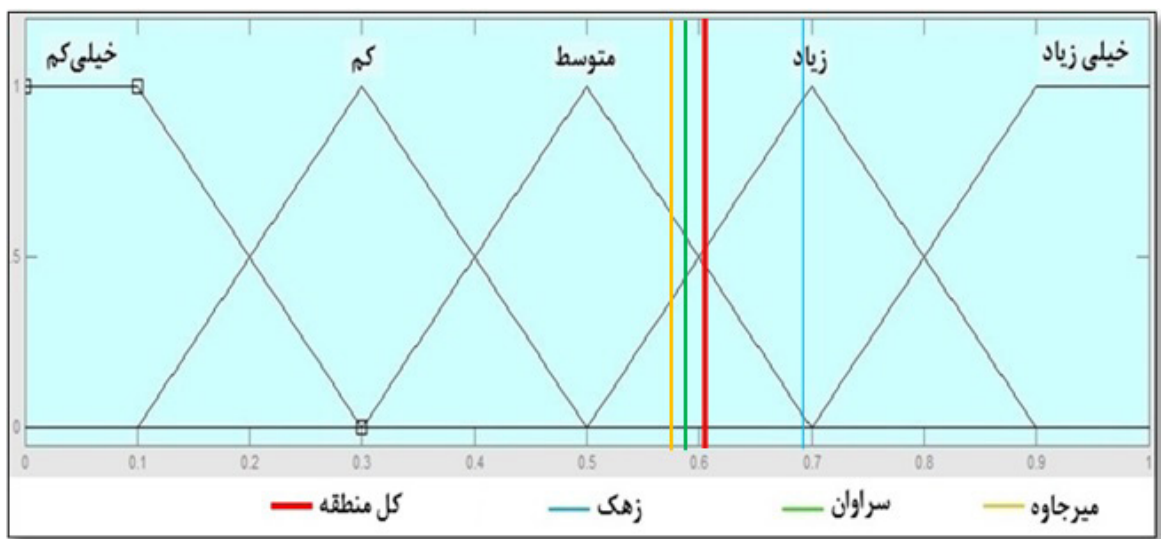




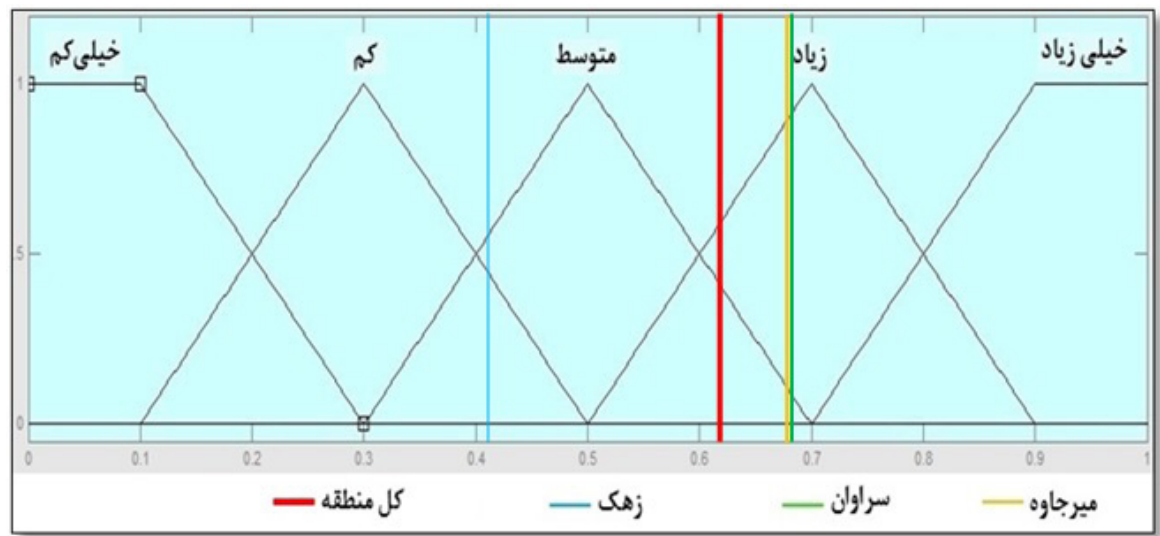

تصوير P. خروجي منطق فازى از ميزان سرمايه اجتماعي در محدوده مطالعشده.

همجنين يافتههاى ركرسيون در بررسى اثر فقر، انسجام

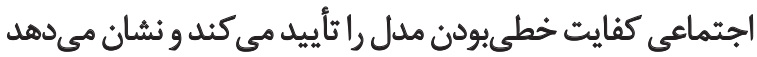

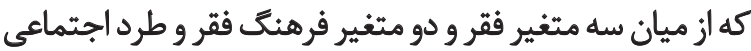

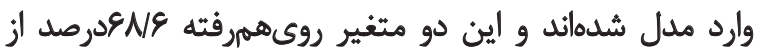

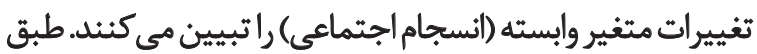

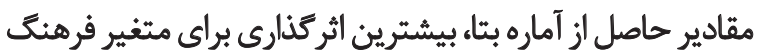

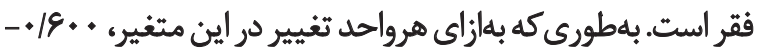

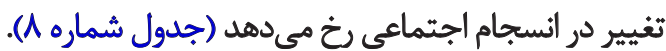

درنهايت ثأثير شاخص كل فقر بر شاخص كل سرمايه اجتماعى

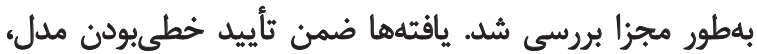

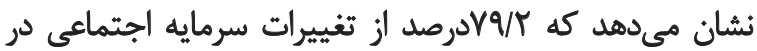

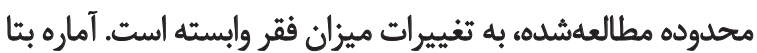

آن به عوامل ديغر مربوط ميىشود. مقادير ضرايب استانداردشده (بتا) نشان مى دهد كه شاخص طرد اجتماعى بيشترين ثأثير كذارى

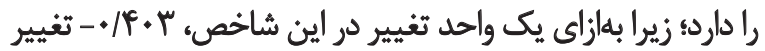
در اعتماد اجتماعى ايجاد مي شود (جدول شماره \&). يافتههاى ركرسيون براى بررسى ثأثير شاخصهاى فقر بر

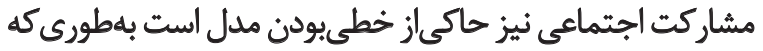

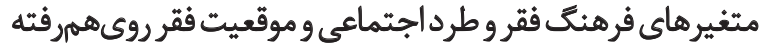

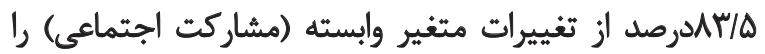

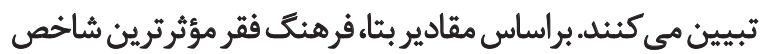

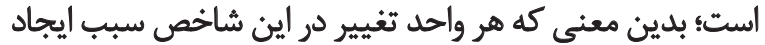

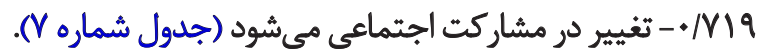

جدول هـ قابليت اجراى ركوسيون متغيرهاى مستمل بر روى متغيرهاى وابسته.

\begin{tabular}{|c|c|c|c|c|c|c|}
\hline Eigenvalue & Condition Index & VIF & Tolerance & Durbin-Watson & مستقل & وابسته \\
\hline$+N \cdot 8$ & $9 / \cdot 1$ & $r / \Delta$ & $\cdot|r A|$ & \multirow{3}{*}{$1 / 09$} & طرد اجتماعى & \multirow{3}{*}{ اعتماد } \\
\hline.$/ * r \cdot$ & $11 / 6$ & $r / f$ & - rar & & فرهنى ققر & \\
\hline .111 & $19 / 8$ & $y / \cdot 9$ & .1914 & & موقعيت فقر & \\
\hline.$/ 1.8$ & $9 / .1$ & $m / f$ & - Mar & \multirow{3}{*}{ VAY } & فرهنى فقر & \multirow{3}{*}{ مشاركت } \\
\hline \%.r. & $11 / / 49$ & $\Psi / \Delta$ & - TrAI & & طرد اجتماعي & \\
\hline$+1+11$ & $\mid f / 8$ & $1 /+9$ &.$(91 \%$ & & موقعيت فقر & \\
\hline $.1+\sqrt{ } 8$ & $8 / 19$ & $r / f$ & (r & \multirow[b]{2}{*}{ V/Fe } & فرهنى فقر & \multirow[b]{2}{*}{ أنسجام } \\
\hline $.1 \cdot 11$ & $\mid r / \Delta E$ & $r / F$ & . & & طرد اجتماعى & \\
\hline $.1 \cdot V^{8}$ & $8 / 19$ & $r / e$ & . Rqu & \multirow{2}{*}{$1 / 8 A$} & فرهنك فقر & \multirow{2}{*}{ سرمايه اجتماعى } \\
\hline $.1 \cdot 11$ & IT/AF & $r / f$ & . rqu & & طرد اجتماعى & \\
\hline 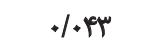 & SN & - & - & $1 / 81$ & فقر & سرمايه اجتماعى \\
\hline
\end{tabular}


جدول و. بررسى عوامل مؤثر بر اعتماد اجتماعى با استفاده از تحليل ركرسيون جئدمتغيره.

\begin{tabular}{|c|c|c|c|c|c|c|c|c|}
\hline sig. & $\mathbf{t}$ & Beta & $\mathbf{R}^{2}$ & $\mathbf{R}$ & كفايت مدل & $\mathbf{F}$ & هتغير هستثل & كام \\
\hline $.1 \%$ & $-V / f$ & $-* / \mu \cdot r$ & . late & . MTE & & arrier & طرد اجتماعى & اول \\
\hline .10. & $-8 / 29$ &.$- / M f^{2}$ & $.1 \Delta \Delta A$ & - Mer &.$\ldots$ & MTA/MT & فُرهنى فقر & دو \\
\hline+10. & $-r / .9$ &.$- / 1 m$ & $.10 V^{2}$ & . NOE & & MVI. 1 & موقعيت فقر & سوم \\
\hline
\end{tabular}

جدول V. بررسى عوامل مؤثر بر مشاركت اجتماعى با استفاده از تحليل ركرسيون جندمتغيره.

\begin{tabular}{|c|c|c|c|c|c|c|c|c|}
\hline Sig. & $\mathbf{t}$ & Beta & $\mathbf{R}^{2}$ & $\mathbf{R}$ & كفايت مدل & $\mathbf{F}$ & متغير مستقل & كام \\
\hline$+\ldots$ & $-r / / A$ & $-\cdot / M 19$ & $\cdot / \lambda \cdot V$ & ./14 & & rIDE/q & فرهنى فقر & اول \\
\hline$+1+$. & $-V / P V$ & $-* / Y \Delta A$ &.$/ 119$ & $\cdot 19 \cdot 0$ & $\%$ & $11 \mathrm{EV} / \mathrm{F}$ & طرد اجتماعي & دوم \\
\hline$+\ldots$ & $-V / r r$ & 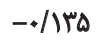 & ./ATD &.$/ 914$ & & $A N / T$ & موقعيت فقر & سوم \\
\hline
\end{tabular}

جدول ^. بررسى عوامل مؤثر بر انسجام اجتماعى با استفاده از تحليل ركّرسيون جيندمتغيره.

\begin{tabular}{|c|c|c|c|c|c|c|c|c|}
\hline Sig. & $t$ & Beta & $\mathbf{R}^{2}$ & $\mathbf{R}$ & كثايت مدل & $\mathbf{F}$ & مثغير مستقل & كام \\
\hline 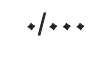 & $-1 r / T$ & $-.18 .$. & - legr & - /Air & $.1 \ldots$ & $1 . r T / 1$ & فرهنَ فُقر & اول \\
\hline 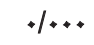 & - Q/ef & $-\pi /$ TAV & - IEN & - /AYA & & $\Delta F / A$ & طرد اجتماعي & دوم \\
\hline
\end{tabular}

جدول جه بررسى ثأثير فقر بر سرمايه اجتماعى با استفاده از ركرسيون خطى.

\begin{tabular}{|c|c|c|c|c|c|c|c|}
\hline Sig. & $\mathbf{t}$ & Beta & $\mathbf{R}^{2}$ & $\mathbf{R}$ & كفايت مدل & $\mathbf{F}$ & متغير مستقل \\
\hline .10. & $-\mu \varphi / r^{\infty}$ & $-+/ 19$. & - Nar & .119. & 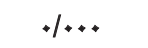 & 198.11 & فقر \\
\hline
\end{tabular}

عوامل در اين رابطه كه نقش محورى دارند و با هم ارتباطى إنى

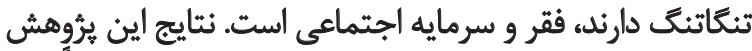

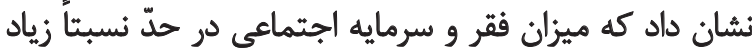

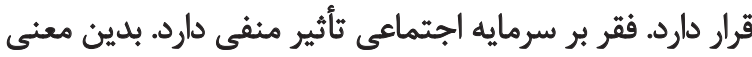

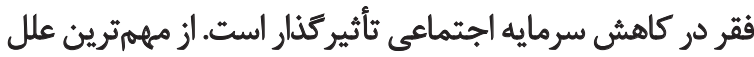

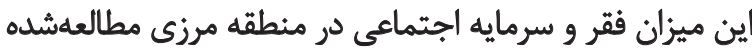

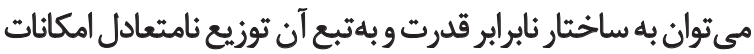

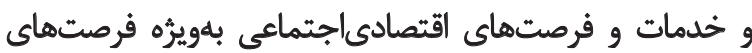

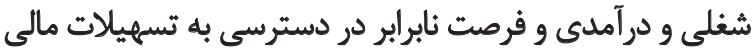

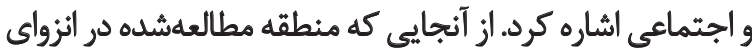

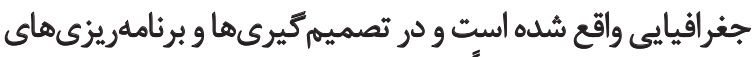

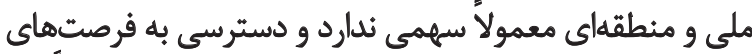

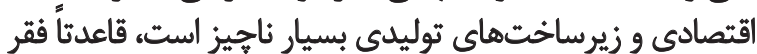

در اين مناطق كسترش مي يابد.
نيز نشان مى دهد كه بلازاى هرواحد تغيير در ميزان فقر در منطقه،

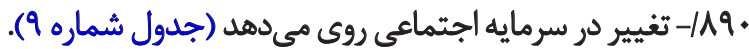

براساس يافتههاى ركرسيون جندمثغيره، فرهنگ فقر در تبيين

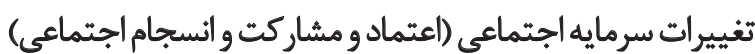

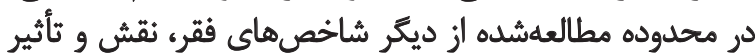

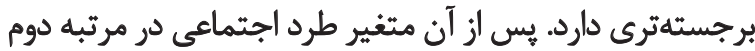

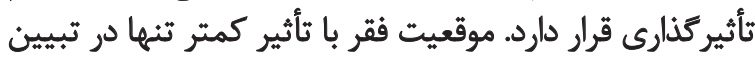

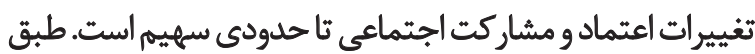
اين يافتهها، فقر تأثير بسيار بالايى در كاهش و و فرسايش سائ سرمايه اجتماعى در اين منطقه مرزى دارد. مناطق مرزى شرق كشور از استان سيستانوبلوجستان درزمره

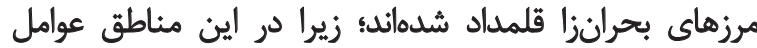

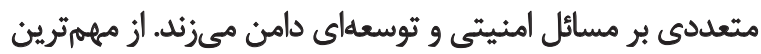




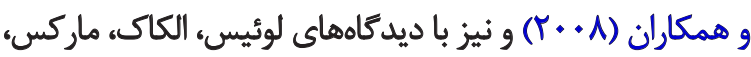

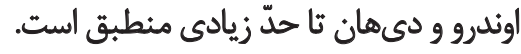

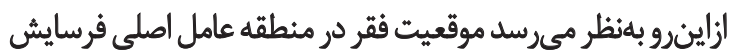

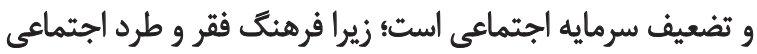

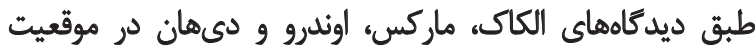

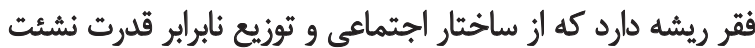

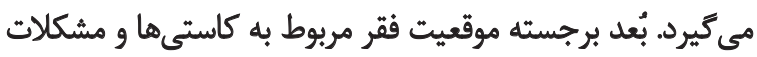
اقتصاد محلى است كه مهمثرين علت فقر در منطقة مطالعهشده براست.

بسيارى از مسائل امنيتي و اقدامات واكرايانه در منطقه نوعى بري

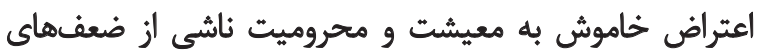

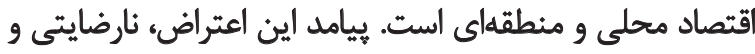

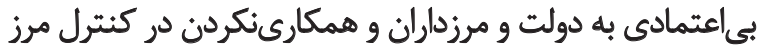

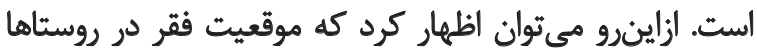

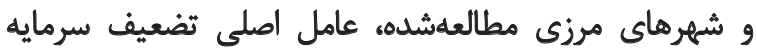

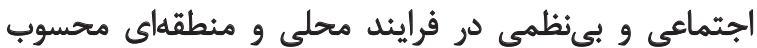

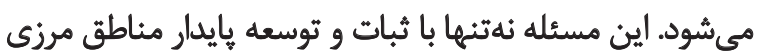

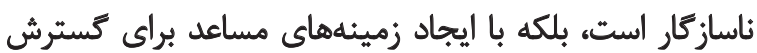

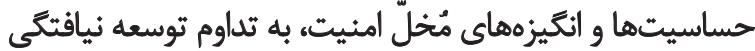

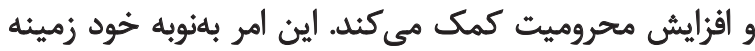

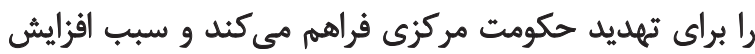
هزينهاي تأمين امنيت مي تيودود.

\section{ه. بحث و نتيجهليَيرى}

مسئله كاهش سرمايه اجتماعى در اثر فقر در محدوده مورد

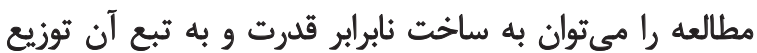

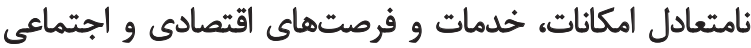

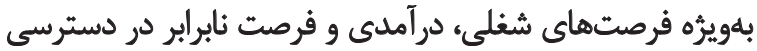

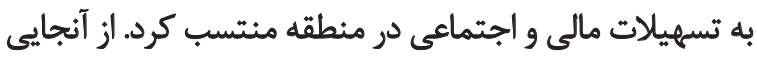

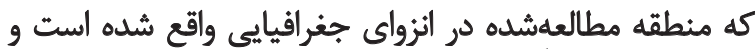

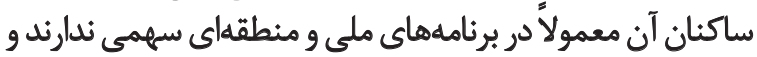

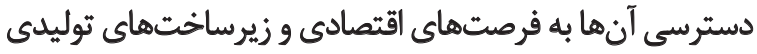

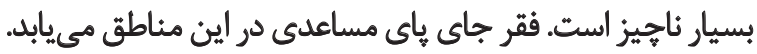

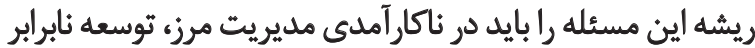

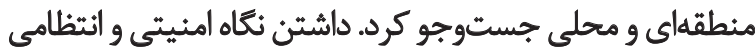

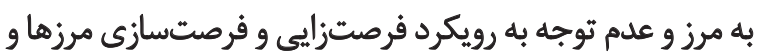

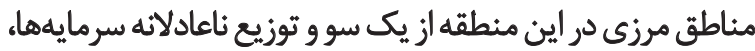

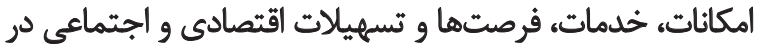

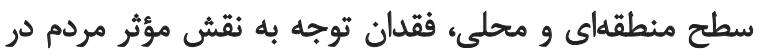

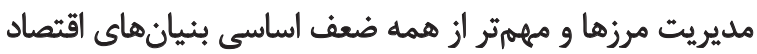

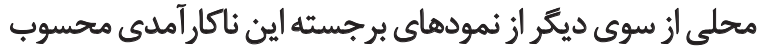

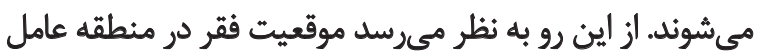

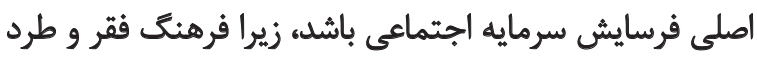

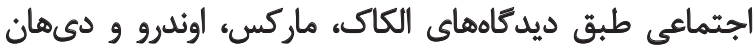

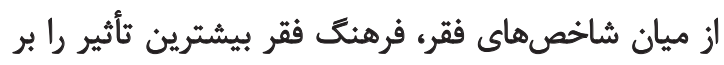

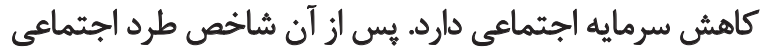

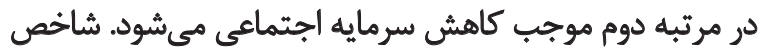

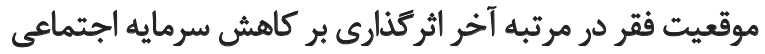

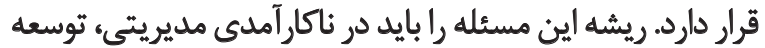

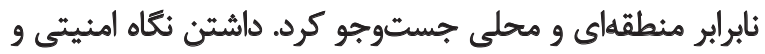

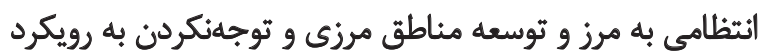

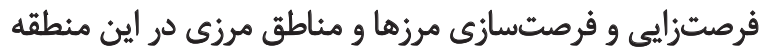

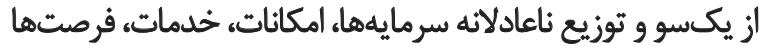

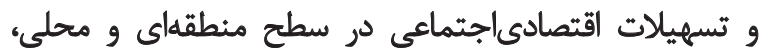

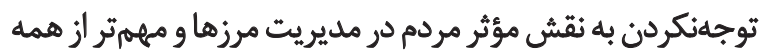

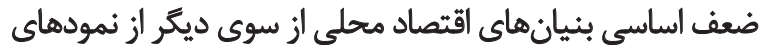

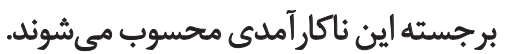

موقعيت عملكردى مرز نمونه ديكرى از اين ناكارآمدى هاست؛

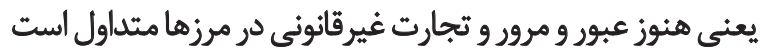

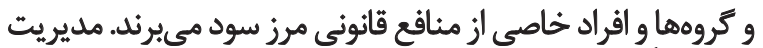

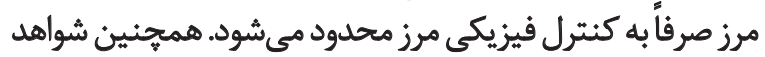

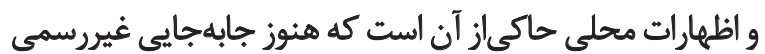

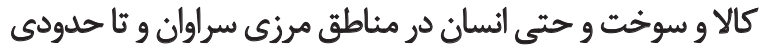

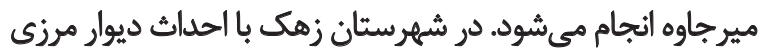

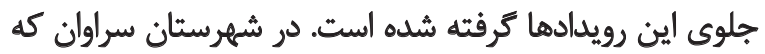

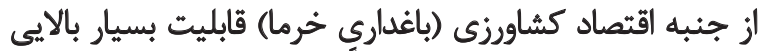

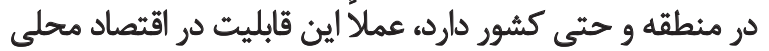

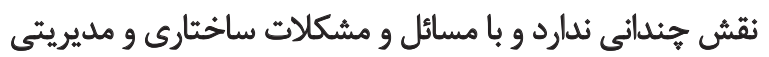

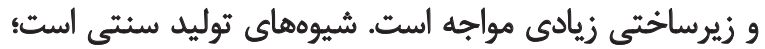

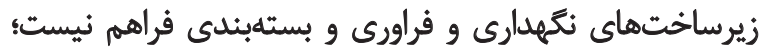

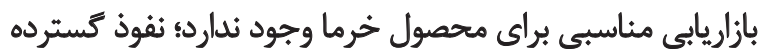

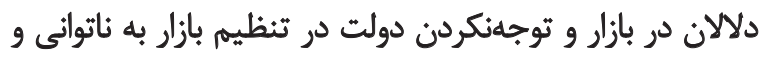
بي انكيزگى توليدكنيدكان منجر شده است.

مسئله كمآبى نيز به اين دلايل افزوده شده است. همجئين در

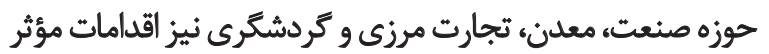

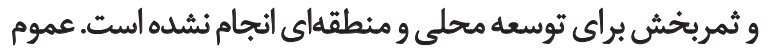

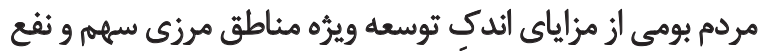

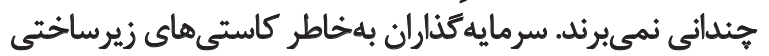

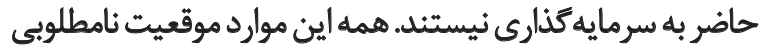

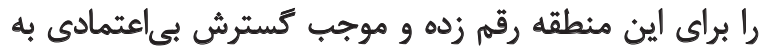

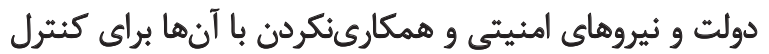

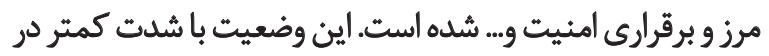

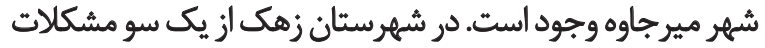

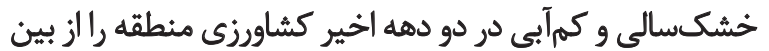

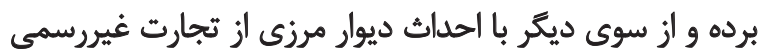

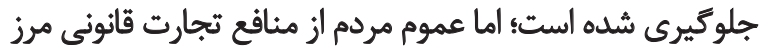
بهرهمند نيستند. اين نتايج با يافتهاي كولير (1991) و زاهدي 


\section{References}

Abdollahi, A., Valaei, M., \& Anvari, A. (2013). [Evaluating the effects of social capital in rural poverty reduction: The village of Kipchak the Miandoab Township (Persian)]. Journal of Spatial Economic and Rural Development, 2(4), 133-52.

Afrough, E. (2000). [The theoretical perspective of class analysis and development (Persian)]. Tehran: Culture of Knowledge.

Ahmadi, H., \& Iman, M. T. (2005). [The culture of poverty, marginalization and tendency towards delinquent behavior among young people marginalized Deh Pialeh of Shiraz in 2004 (Persian)]. Journal of Isfahan University (Human Sciences), 19(2), 118-99.

Al-Jarrah, O., \& Abu-Qdais, H. (2006). Municipal solid waste landfill sitting using intelligent system. Waste Management, 26(3), 299-306. doi: 10.1016/j.wasman.2005.01.026

Alexiedou, N. (2005). Social exclusion, and educational opportunity: the case of British education policies within a European Union context. Globalisation, Societies and Education, 3(1), 101-125. doi: 10.1080/14767720500046351

Bourdieu, P. (1986). The forms of capital. In J. G. Richardson (ed.), Handbook of Theory and Research for the sociology of Education (pp. 241-58). New York: Greenwood Publishing Group.

Basatyan, S. M. (2011). [Investigating pattern off the culture of poverty, and its related factors: Case study Delfan Township of Lorestan Province (Persian)]. Journal of Social Problems of Iran, 2(2), 7-32.

Coleman, J. (1998). The foundations of social theory [M. Saburi, (Persian trans.)]. Tehran: Ney Publication.

Collier, P. (1998). Social capital and poverty. Washington, D. C.: World Bank.

de Haan, A. (2001). Social exclusion: enriching the understanding of deprivation (Report). Brighton: University of Sussex.

Esfandiari, I. (2013). [The poverty and social deviationscontexts or motivation (Persian)]. Journal of Women's Strategic Studies, 6(21), $1-32$.

Field, J. (2007). Social capital [G. R. Ghaffari \& H. Ramezani, (Persian trans.)]. Tehran: Kavir Publication.

Fukuyama, F. (2006). The end of discipline, social capital and maintain it [Gh. A. Tavasoli, (Persian trans.)]. Tehran: Hekayat Publication.

Ghaffari, G., \& Tajoddin, M. B. (2005). [The enquiry of social deprivation dimensions (Persian)]. Social Welfare Quarterly, 5(17), 29-52.

Gregory, D., Johnston, R., Pratt, G., Watts, M., \& Whatmore, S. (2009). The dictionary of human geography ( $5^{\text {th }}$ ed.). New Jersey: John Wiley \& Sons Publications.

Grootaert, C. (1999). Social capital, household welfare and poverty in Indonesia. Washington, D. C.: World Bank.

Grootaert, C., \& Narayan, D. (2004). Local institutions, poverty and household welfare in Bolivia. World Development, 32(7), 1179-198. doi: 10.1016/j.worlddev.2004.02.001

Hafeznia, M. R. (2002). [Political geography of Iran (Persian)]. Tehran: Samt Publications.

$$
\text { قديشه در موقعيت فقر دارد كه از ساخت اجتماعى و توزيع نابرابر }
$$

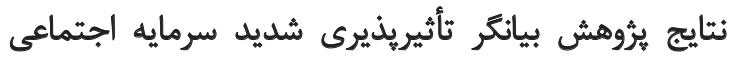

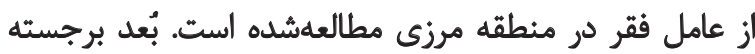

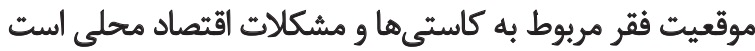

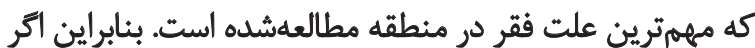

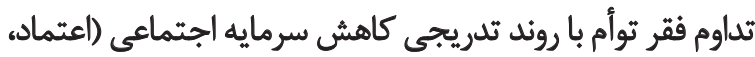

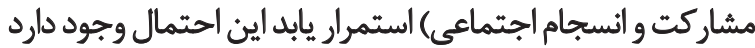

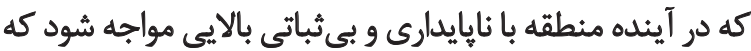

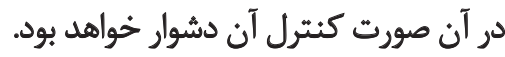

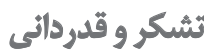
اين مقاله حامى مالى ندارد. 
Hamzaei, M. R., Shah Hoseini, A., Borzoo, G. R., Mousavi, S. (2012). [Poverty culture among villagers of Harsin township (Persian)]. Social Welfare Quarterly, 12(45), 238-73.

Ismail-Zadeh, Kh. (2008). [Anthropological study border common markets with the approach of economic anthropology (Persian)]. Iranian Journal of Anthropology , 5(9), 38-65.

Kalantari, S., Rabbani, R., \& Sedaghat, K. (2005). [The relation between poverty and illigality construction of social pathogens (Persian)]. Social Welfare Quarterly, 5(18), 65-90.

Kordestani, G. R., \& Rahimi, M. (2009). [The application of fuzzy logic in accounting and financial decisions (Persian)]. Hesabras, 11(47), 86-93.

Lemmi A., \& Gianni, B. (2006). Fuzzy set approach to multidimensional poverty measurement. Berlin, Heidelberg: Springer Science Business Media.

Lin, N. (2001). Social capital: A theory of structure and action. Cambridge: Cambridge University Press.

Moore, B. (2000). 'No child': Child poverty: The facts: A summary. Fitzroy, Victoria: Brotherhood of St. Laurence.

Morris, M. (1998). Social capital and poverty in India. Brighton: Institute of Development Studies.

Mukaila, A., Sakariyau, O., Dauda, C., Paiko, I., Zubairu, U. (2012). Social capital and poverty reduction in Nigeria: A case study of Minna metropolis. International Journal of Business and Social Science, 3(12), 229-236.

Putnam, R. (1995). Bowling alone: America's declining social capital. Journal of Democracy, 6(1), 65-78.

Saligheh, M., Barimani, F., \& Ismail Negad, M. (2008). [Climatical regionalization on Sistan \& Baluchestan Province (Persian)]. Journal of Geography and Development, 6(12), 101-06.

Shaditalab, Zh., \& Hoijati Kermani, F. (2008). [The relation of social capital with poverty (Persian)]. Social Welfare Quarterly, 7(28), 3556.

Shayani, M. (2005). [Poverty, deprivatio and citizenship in Iran (Persian)]. Social Welfare Quarterly, 5(18), 41-64.

Singer, P. (2009). The life you can save: Acting now to end world poverty. New York: Random House Publications.

Statistical Center of Iran, (2011). Statistical Yearbook of Sistan and Baluchestan Province. Tehran: Statistical Center of Iran.

Warf, B. (2006). Encyclopedia of human geography. Thousand Oaks, California: Sage Publications.

Zahedi, M. J. (2007). [Development and inequality (Persian)]. Tehran: Maziar Publications.

Zahedi, M. J., Maleki, A., \& Heydari, A. A. (2008). [Poverty and social capital (Persian)]. Social Welfare Quarterly, 7(28), 79-106. 